NBER WORKING PAPER SERIES

MONEY-BACK GUARANTEES IN INDIVIDUAL RETIREMENT ACCOUNTS:
STILL A GOOD DEAL?

\author{
Vanya Horneff \\ Daniel Liebler \\ Raimond Maurer \\ Olivia S. Mitchell \\ Working Paper 26406 \\ http://www.nber.org/papers/w26406 \\ NATIONAL BUREAU OF ECONOMIC RESEARCH \\ 1050 Massachusetts Avenue \\ Cambridge, MA 02138 \\ October 2019, Revised March 2021
}

Previously circulated as "Implications of Money-Back Guarantees for Individual Retirement Accounts: Protection Then and Now." The authors are grateful for research support from the German Investment and Asset Management Association (BVI), the Leibniz Institute for Financial Research SAFE funded by the State of Hessen, and the Pension Research Council/Boettner Center at The Wharton School of the University of Pennsylvania. We thank the Competence Center for High Performance Computing in Hessen for granting us computing time on the Goethe-HLR and Lichtenberg Cluster. Data were generously provided by the German SocioEconomic Panel and the Deutsche Bundesbank Panel on Household Finances. Opinions and any errors are solely those of the authors and not of the institutions with which the authors are affiliated, nor of any individual cited, nor of the National Bureau of Economic Research.

At least one co-author has disclosed additional relationships of potential relevance for this research. Further information is available online at http://www.nber.org/papers/w26406.ack

NBER working papers are circulated for discussion and comment purposes. They have not been peer-reviewed or been subject to the review by the NBER Board of Directors that accompanies official NBER publications.

(C) 2019 by Vanya Horneff, Daniel Liebler, Raimond Maurer, and Olivia S. Mitchell. All rights reserved. Short sections of text, not to exceed two paragraphs, may be quoted without explicit permission provided that full credit, including $\odot$ notice, is given to the source. 
Money-Back Guarantees in Individual Retirement Accounts: Still a Good Deal?

Vanya Horneff, Daniel Liebler, Raimond Maurer, and Olivia S. Mitchell

NBER Working Paper No. 26406

October 2019, Revised March 2021

JEL No. D14,D91,G11,G5,G52

\begin{abstract}
Capital market volatility spurs interest in protecting retirement accounts; one such approach is to require money-back guarantees. Using a lifecycle model where investors have access to stocks, bonds, and tax-qualified retirement accounts, we show that such guarantees alter participant consumption, saving, and investment behavior during times of high interest rates, but impacts are even larger in a low-return environment. We conclude that abandoning guarantees could enhance old-age consumption for over $80 \%$ of retirees, particularly lower earners, without harming pre-retirement consumption. Our results are of interest for default investment options in individual retirement accounts such as the Pan-European Personal Pension Products.
\end{abstract}

\author{
Vanya Horneff \\ Goethe University Frankfurt \\ Finance Department \\ Theodor-W. Adorno Platz 3 \\ House of Finance \\ 60323 Frankfurt \\ Germany \\ vhorneff@finance.uni-frankfurt.de \\ Daniel Liebler \\ Goethe University Frankfurt \\ Finance Department \\ Theodor-W. Adorno Platz 3 \\ 60323 Frankfurt am Main \\ Germany \\ liebler@finance.uni-frankfurt.de
}

\author{
Raimond Maurer \\ Goethe University Frankfurt \\ Finance Department \\ Theodor-W. Adorno Platz 3 \\ 60323 Frankfurt am Main \\ Germany \\ maurer@finance.uni-frankfurt.de \\ Olivia S. Mitchell \\ University of Pennsylvania \\ The Wharton School \\ 3620 Locust Walk, St 3000 SH-DH \\ Philadelphia, PA 19104-6302 \\ and NBER \\ mitchelo@wharton.upenn.edu
}




\section{Money-Back Guarantees in Individual Retirement Accounts: Still a Good Deal?}

\section{Introduction}

Numerous countries have adopted tax-qualified defined contribution retirement accounts as a means to fill the gap between retiree income needs and benefits payable under national social security systems. ${ }^{1}$ Additionally, many policymakers seek mechanisms to protect savers against longevity risk and capital market volatility, and one approach has been to require money-back guarantees for participant contributions. Thus, private financial institutions in Europe have offered principal guarantees at market prices (Maurer and Schlag, 2003), Japanese defined contribution plans are required by law to offer at least one guaranteed account (Allianz Global Investors, nd), and several Latin American nations have instituted government guarantees for pension savings (e.g. Pennacchi, 1999; Fischer, 1999).

From a policy perspective, requiring retirement account guarantees can be rationalized if they are conducive to achieving high-priority goals. For example, requiring money-back guarantees might serve the purpose of fostering private savings, which could reduce retirees' dependence on state pensions already stressed by population aging (Mercer, 2020). There is also evidence that many workers are financially unsophisticated and loss averse, both factors that deter them from saving and investing in the capital market (e.g., Lusardi and Mitchell, 2014; Haliassos and Bertaut, 1995; Abdellaoui et al., 2007). Moreover, Calvet et al. (2020) showed that providing people access to equity-linked products with a capital guarantee boosted stock market participation and portfolio returns, especially for loss averse households. Additionally, since women live longer yet tend to be more loss averse than men (Schmidt and

\footnotetext{
${ }^{1}$ For instance, defined contribution or $401(\mathrm{k})$ retirement saving plans in the U.S. are the primary tax-qualified mechanism helping private sector workers accumulate retirement assets, now totaling over $\$ 5$ trillion (ICI, 2018). Ernst \& Young (2017) recently showed that individual retirement accounts are available in most European Union countries, though the market is highly fragmented across member states. Total assets under management amount to $€ 600$ billion, of which most, $€ 224$ billion, is held by the German Riester IRAs.
} 
Traub, 2002), including money-back guarantees in their retirement plan menus could enhance their willingness to participate in pension accounts. ${ }^{2}$

As a case in point, the European Parliament (2019) recently adopted a European Commission (2017) proposal to establish a Pan-European Personal Pension Product (PEPP), a standardized tax-qualified funded defined contribution plan offered by financial institutions such as asset managers, life insurers, and banks. These accounts - conceptually comparable to the U.S. Individual Retirement Accounts (IRAs) - are intended to encourage retirement savings and allow pension portability for over 200 million workers across the European Union. During the worker's accumulation phase, a provider must offer a default option (called the Basic PEPP) which governs the plan's investment strategy when the saver provides no instructions on how to invest the funds. Besides a yearly cap on fees and expenses of $1 \%$ of accumulated capital, this default option requires capital protection, either in form of a money-back guarantee from the provider, or another risk mitigation technique ensuring that the PEPP saver can recoup the funds contributed by the end of the accumulation phase.

Nevertheless, while such investment guarantees can protect against shortfall risk and longevity risk to protect financially-illiterate workers, the economic costs of such guarantees must be properly understood. In the early part of the $21^{\text {st }}$ century, for instance, money-back guarantees would have cost around 5\% of annual contributions for U.S. Individual Retirement Accounts (IRAs) (Lachance and Mitchell, 2003). Yet that research was conducted in the context of a much higher interest rate environment than is presently the case; since low returns now appear to be persistent (Horneff et al., 2018), these costs should be reevaluated to determine if they are now more substantial and might adversely impact their intended effect, which is to enhance old-age security of private households.

\footnotetext{
${ }^{2}$ Célérier and Vallée (2017) show that catering to the behavioral traits of households is an effective means to encourage them to invest in savings products, and that this increases the profitability of providers.
} 
Previous research is also silent on how such guarantees could shape behavior in the context of a life cycle framework with endogenous consumption, saving, and portfolio allocation and location decisions: this is the subject of the present paper. Accordingly, a key contribution of our study is to build a general model which we use to assess the costs and benefits of a mandatory money-back pension guarantee. We also examine how such guarantees affect saving and investment behavior inside and outside of such accounts, and retirement wellbeing, while incorporating important aspects of the tax structure, social security benefits, and capital markets (e.g., Cocco and Gomes, 2012; Horneff et al., 2015, 2018). Our research, therefore, contributes to the rich literature on financial decisionmaking of private households (see Gomes et al., 2020a, for an overview) using dynamic consumption and portfolio choice models in discrete time.

As mentioned by Gomes (2020) it is important to develop models that capture the relevant institutional features of retirememt savings, especially with respect to the tax and the national social-security system. With respect to the institutional framework, we evaluate the case of the IRAs adopted in Germany in 2002 under the Riester program. ${ }^{3}$ This program permits offering tax-qualified individual retirement accounts, as long as these include embedded mandatory money-back guarantees. Such accounts are popular, with over 35\% of eligible German employees holding contracts, making them more prevalent than occupational pensions (BörschSupan et al., 2012; 2015). Not only do product providers promise participants a money-back guarantee during the accumulation phase, but the government also subsidizes contributions (to a cap) by workers in the form of deferred taxation and direct subsidies. In retirement, benefits must be paid as guaranteed lifetime income streams.

\footnotetext{
${ }^{3}$ While for the member states of the Euro area the assumption of a uniform capital market with similar interest rates is reasonable, the institutional framework with respect to the tax and social security systems is still different (in contrast to the $50 \mathrm{U} . \mathrm{S}$. states). In this respect, it is necessary to focus on one country. In Online Appendix F, we also address the extent to which the results may be transferable to other countries.
} 
Our goal is to determine optimal consumption, stock and bond holdings, and contributions into and withdrawals from the Riester accounts, taking into account capital market shocks, uncertainty about labor income and remaining lifetimes, and the rich institutional details relevant to the tax and social security benefit structure. We then compare results with and without the money-back guarantees, in both 'normal' and 'low return' environments.

We provide four main findings. First, during what we call 'historically normal' capital market periods, money-back guarantees had only a modest effect on consumption prior to retirement, but they did reduce post-retirement consumption for about $82.4 \%$ of retirees by an average of $2.9 \%$ per year (or $€ 430$ annually). This means that eliminating these money-back guarantees would have boosted old-age consumption for most elderly, even prior to the current low return regime. Second, in a low interest environment, this type of guarantee has a more complex impact. On the one hand, many people do benefit from the account guarantee: the shortfall probability of losing money at age 67 without the guarantee is $18.1 \%$, compared to $6.4 \%$ in the 'normal' capital market environment. Yet the costs of protection are so high that $81.3 \%$ of retirees end up with markedly lower old-age consumption, by an average of $8.3 \%$ (or $€ 950$ per year). In addition, consumption during the worklife is also slightly lower with the guarantee. Third, we show whether implementing an age-based life cycle investment approach would be a better risk mitigation technique, compared to the money-back guarantee. During a 'normal' capital market, we find that life cycle funds provided less lifetime consumption than guaranteed accounts. But under current market conditions, a life cycle fund with sufficiently high equity exposure generates greater average old-age consumption than can be expected under the money-back guarantee. Fourth, in adverse capital market scenarios, the protection provided by guaranteed IRAs is lower than anticipated. Even if the stock market dropped by $35 \%$ in workers' last year of employment, most participants would, surprisingly, be worse off compared to not having a guarantee. The reason is that the costs of providing the guarantee erode the account's asset base, relative to unprotected schemes. 


\section{Riester Individual Retirement Accounts with Money-Back Guarantees}

\subsection{Eligibility, Incentives, and Institutional Framework}

In 2018, 45 million German employees were entitled to contribute to tax-qualified Riester IRAs, and 16.6 million people held this type of contract (BMAS, 2017). Two complementary subsidies incentivize workers to save for retirement using such accounts. ${ }^{4}$ First, the federal government pays a yearly subsidy into each worker's IRA of up to $€ 175$ plus $€ 300$ per child younger than age 25. To qualify for the full subsidy, the sum of employee contributions plus subsidies must equal $4 \%$ of pre-tax labor income (to a cap of $€ 2,100$ ). If the threshold of $4 \%$ is not met, subsidies are reduced proportionally. Subsidies on personal pension contributions are also common in the United States, often taking the form of employer matching of contributions up to some limit (ICI, 2021). Second, employees earning higher incomes can benefit from deferred taxation; that is, IRA contributions to an annual cap of $€ 2,100$ are paid from pre-tax income, and investment earnings on account assets are tax-exempt. ${ }^{5}$ In all cases, retirement withdrawals are subject to income tax.

Approximately $65 \%$ of Riester contracts are held with life insurers, $20 \%$ with asset managers, and 5\% with banks; the dominant form is accumulation/decumulation plans of financial assets which are the focus of this paper. ${ }^{6}$ Providers of these contracts must abide by investment and income guarantee rules codified in the 'Certification of Retirement Pension Contracts Act.' Specifically, during the decumulation phase: (i) payouts are allowed only from age 62 onwards; (ii) not more than $30 \%$ of accumulated assets may be withdrawn as a lump sum; (iii) the remaining assets must be distributed as lifelong non-decreasing guaranteed nominal benefits; and (iv) mandatory annuitization is required by age 85 (at the latest) of the retiree's remaining capital. Usually, to fulfill the last requirement, IRA providers devote a share

\footnotetext{
${ }^{4}$ For an overview of the government incentives to engage in Riester plans see Börsch-Supan et al. (2008).

${ }^{5}$ The German tax authorities check whether the deductibility of contributions is more favorable than subsidies and settles corresponding differences through tax refunds.

${ }^{6}$ Banks also offer Riester IRAs in the form of special mortgage loan contracts, and they have a $10 \%$ market share.
} 
of savers' balances at age 67 to buy a deferred annuity paying benefits to the retiree from age 85 until death. ${ }^{7}$ In addition, product providers must offer a money-back guarantee: that is, if at the end of the accumulation phase, the account value is lower than the sum of payments into the IRA, the provider must cover the shortfall using its equity capital.

Following a strong initial market penetration, the number of contracts has stagnated since 2012, though it is unclear whether market saturation or declining appeal in the low interest rate environment is the main driver. In particular, the investment and income guarantees for Riester IRAs have become considerably more expensive since the scheme was adopted in 2002. The main explanation for this is that the European Central Bank's quantitative easing strategy has caused interest rates to plummet from a historical norm of about $3 \%$, down to the current $0 \%$ (or even negative) nominal rate. One result is that premiums for mandatory annuitization have become increasingly expensive. For example, the price of a deferred annuity purchased at age 67 paying lifelong benefits of $€ 1$ from age 85 onward rose from $€ 1.59$ (with an assumed interest rate of $3 \%$ ) to $€ 2.92$ (at a $0 \%$ interest rate). Another is that the low interest environment has also led to a substantial increase in the costs of hedging the money-back guarantee.

\subsection{Costs of Money-Back IRA Guarantees}

To illustrate how pricing works for the money-back guarantee, we apply option pricing techniques for a simplified IRA that omits optimal choice of annual contributions, as well as the plan's impact on consumption and the demand for liquid savings, following Lachance and Mitchell (2003). In subsequent sections, we shall elaborate the model further.

We assume constant annual contributions $A_{t}(t=1, \ldots, T)$ by the plan participant until the end of the accumulation phase at time $T$, and the plan provider is obliged to compensate for any losses below the sum of contributions as of date $T$. The put hedging approach allows the

\footnotetext{
${ }^{7}$ This does not necessarily correspond to optimal timing of the deferred annuity purchases (Huang et al., 2016), but it relieves the product provider from bearing some of the risk of holding equity capital to ensure non-decreasing payouts after age 85 .
} 
provider to offer clients participation in the stock market, while partly transferring shortfall risks of not achieving the guaranteed amount to the capital markets. Formally, yearly contributions $A_{t}$ are used to buy $u_{t}$ units of an equity portfolio (represented by a diversified stock index) with price $S_{t}$ plus the same number of at-the-money European put options with price $P_{t}$ and maturity at the end of the saving phase, i.e. $A_{t}=u_{t} S_{t}+u_{t} P_{t}$. Units of the equity portfolio are allocated to the plan participant's IRA. If the value of the equity portfolio is lower than the sum of contributions, the provider must pay the difference, equal to $\max \left(\sum_{t=1}^{T} A_{t}-\right.$ $\left.\sum_{t=1}^{T} u_{t} S_{T}, 0\right)$ into the participant's IRA; this produces an uncertain final IRA value at time $T$ of $\max \left(\sum_{t=1}^{T} u_{t} S_{T}, \sum_{t=1}^{T} A_{t}\right)$. The put premiums charged by the provider from the participant's contributions are the cost of the money-back guarantee (Lachance and Mitchell, 2003).

To quantify hedging costs for plan participants, we generate 100,000 Monte Carlo simulation paths, along with the resulting profit and loss $(\mathrm{P} \& \mathrm{~L})$ position of the plan provider. We posit that the stochastic dynamics of equity investments follow a geometric Brownian motion; moreover, consistent with the life cycle model discussed below, we assume a volatility of $21.41 \%$ and a risk premium of $6 \%$ per year. Put option premiums are calculated using the Black and Scholes (1973) approach under both a 'normal' interest rate environment $\left(i_{f}=3 \%\right)$ and the current low interest rate scenario $\left(i_{f}=0 \%\right)$. Table 1 summarizes the guarantee costs for plan participants, expected guarantee payouts, and the expected P\&L for the plan provider, for different time horizons and the two interest rate assumptions.

\section{Table 1 here}

Panel A of Table 1 addresses the cost of the guarantee from the participants' perspective. At an interest rate of $3 \%$, guarantee costs as a share of total contributions average $9.7-11.2 \%$, depending on the plan's investment horizon. At lower interest rates, guarantee costs increase since the put options become more expensive. For instance, if the interest rate were $0 \%$ and the horizon 42 years (coincident with the Riester pension accumulation phase), one third (35.8\%) 
of annual contributions on average would need to be devoted to put options; over a 10 year horizon, the premiums would amount to $19 \%$ of annual contributions. Panel B indicates that, in the $3 \%$ interest rate environment, expected guarantee payouts to the plan participant (as a percentage of total contributions) are lowest for long plan horizons, since the portfolio value is less likely to fall short of the guarantee amount.

For low interest rates, the larger share of contributions spent on put premiums effectively reduces the worker's asset base and increases guarantee payments from the provider to the client. In all scenarios, guarantee payments are lower than the put premiums charged to the participants. Hence in expectation, the provider might make a profit if the premiums were charged to the client but not used to buy put options. For instance, at the longest plan horizon of 42 years, ${ }^{8}$ guarantee costs exceed payouts by $6.6 \%$ at a $3 \%$ interest rate, and by $13.9 \%$ in the $0 \%$ interest rate scenario. Of course, such a strategy would result in substantial downside risks to regulatory solvency capital requirements for the provider. ${ }^{9}$

Even if the provider does buy options to hedge the risk of payment obligations from the money-back guarantee, gains and losses can still be incurred since the amount required to fulfill the liability to compensate shortfalls in a participant's account may deviate considerably from the option payoffs. ${ }^{10}$ The resulting expected profit/loss appears in Panel C (again expressed in terms of contributions). At a 3\% interest rate, the provider expects to suffer losses only for short investment horizons, and its $\mathrm{P} \& \mathrm{~L}$ becomes more positive, the longer the investment horizon. That is, over a plan life of 42 years, the provider earns an expected gain of $2.2 \%$ of contributions. Conversely, at a $0 \%$ interest rate, the P\&L worsens as the investment horizon

\footnotetext{
${ }^{8}$ Options of such long maturities cannot be bought in markets, yet asset managers could buy replication portfolios. ${ }^{9}$ Depending on its legal structure, a provider is required to hold regulatory solvency capital to cover possible liabilities from the money-back guarantee: regulations vary for banks (according to the Capital Requirement Directive), life insurers (according to the Solvency II framework, see Van Hulle, 2019), and asset managers (according to circular 2/2007 by the Federal Financial Supervisory Authority).

${ }^{10}$ Losses occur if put payoffs do not suffice to compensate for shortfalls in client accounts, e.g. in downwardtrending markets. Gains result from volatile markets when puts bought at high stock index values in intermediate periods pay off, while no or little compensation payments are made to clients due to a positive account development.
} 
lengthens, and no gains occur in expectation as initially high option premiums permit only relatively small investments in the equity index. Thus, strikingly, in the $0 \%$ interest scenario, even if the saving plan lasted for 42 years, losses of $7 \%$ of contributions would be expected.

It is not surprising that rising hedging costs in the low interest rate environment have prompted those offering Riester pensions to question their ability to continue supplying the market. ${ }^{11}$ While most savers still seem to favor guarantees, ${ }^{12}$ plan provider concerns about the viability of the guaranteed IRA market could come to undermine the future of the funded private pension system as a complement to the statutory pay-as-you-go old-age scheme. In what follows, we assess whether abolishing these guarantee features could ultimately improve savers' financial wellbeing.

\section{Money-Back IRA Guarantees in a Life Cycle Model}

Evaluating how mandatory money-back guarantees in IRAs impact workers' saving, investment, and consumption patterns requires building and calibrating a discrete-time life cycle model of consumption and portfolio choice. We do so by positing that the utilitymaximizing worker decides how much to consume and to invest in risky stocks, risk-free bonds, and tax-qualified IRAs. Our framework incorporates key aspects of the German tax structure, social security system, labor income processes, and capital market behavior.

\subsection{Preferences and Optimization}

We consider an individual who lives from time $t=1$ (age 25) to $t=T=76$ (age 100) and retires at $t=K=43$ (age 67, the regular retirement age). Utility is measured by a timeseparable CRRA utility function with constant relative risk aversion $\gamma$, defined over yearly spending for consumption $C_{t}$, and deflated by a consumer price index $\Pi_{t}=\Pi_{t-1}(1+\pi)$. The

\footnotetext{
${ }^{11}$ Moreover, the German asset managers tend to be subsidiaries of major commercial banks which have also become subject to increasingly tight equity capital requirements in the European context.

${ }^{12}$ Union Investment (2018) reported that $88 \%$ of their IRA participants said they favored IRAs with money-back guarantees over otherwise identical IRAs without guarantees.
} 
price index is assumed to evolve at a constant and deterministic rate of inflation, $\pi$, and $\Pi_{0}$ is normalized to one. Inflation effectively devalues the IRA's money-back guarantee due to the fact that it is a nominal rather than an inflation-adjusted promise. Accordingly, the model cannot be solved entirely in real terms but instead requires explicit treatment of inflation as in Koijen et al. (2011). ${ }^{13}$

The subjective one-period discount factor is denoted $\beta$ and the conditional survival probability from period $t$ to period $t+1$ is $p_{t}$. Survival probabilities are taken from the population mortality table provided by the German Federal Statistical Office. The value function $J_{t}$ depends on current realizations of the state variables: these comprise cash on hand, $X_{t}^{R}$ (in real terms); the value of the Riester account, $I R A_{t}$; the guaranteed amount (i.e. the sum of contributions and subsidies), $G_{t}$; the annual payout of the deferred annuity after age $85, D_{t}$; and the labor/retirement income states, $s_{t}$. Expected lifetime utility is maximized by solving the recursive Bellman equation with respect to real consumption, $C_{t} / \Pi_{t}$, stock investment, $S_{t}$, bond investment, $B_{t}$, the IRA contribution, $A_{t}$, and lump sum withdrawals $W_{L S}$ from IRAs:

$$
\begin{aligned}
& J_{t}\left(X_{t}^{R}, I R A_{t}, G_{t}, D_{t}, S_{t}\right)= \\
& \max _{C_{t}, S_{t} B_{t}, A_{t}, W_{L S}}\left\{\frac{\left(C_{t} / \Pi_{t}\right)^{1-\gamma}}{1-\gamma}+\beta p_{t} \mathbb{E}_{t}\left[J_{t+1}\left(X_{t+1}^{R}, I R A_{t+1}, G_{t+1}, D_{t+1}, s_{t+1}\right)\right]\right\} .
\end{aligned}
$$

Presuming the common short-sale and borrowing constraints implies non-negativity of all control variables, such that:

$$
C_{t}, S_{t}, B_{t}, A_{t}, W_{L S} \geq 0
$$

With up to five state variables (excluding time $t$ ), this model is computationally expensive to solve. To mitigate the curse of dimensionality, we discretize the labor income process to $n_{s}$ age-dependent levels; this implies that $n_{s}$ times as many optimization problems

\footnotetext{
${ }^{13}$ Our model is solved in a nominal world (i.e. all income figures, tax allowances, etc. grow at the rate of inflation) and the effect of inflation in the intertemporal tradeoff between consuming now and in the future is considered by optimizing real consumption. Results shown in figures and tables are converted back to real terms at the end of the subsequent simulation procedure.
} 
must be solved relative to a continuous income process, but we benefit from interpolating through one fewer dimension in the computation of the value function, yielding a considerable reduction in execution time.

Transitions between discretized income states are governed by a Markov chain, ${ }^{14}$ where $q_{s_{t}, s_{t+1}}$ denotes the probability of migrating from a current income state $s_{t}$ to a subsequent period's state $s_{t+1}$. Consequently, the expectation of the value function $\mathbb{E}_{t}\left[J_{t+1}(\cdot)\right]$ is the probability-weighted average of future value functions given today's income state $s_{t}$ and transition probabilities $q_{s_{t}, s_{t+1}}$ :

$$
\mathbb{E}_{t}\left[J_{t+1}(\cdot)\right]=\sum_{s} q_{s_{t}, s} \mathbb{E}_{t}\left[J_{t+1}\left(X_{t+1}^{R}, I R A_{t+1}, G_{t+1}, D_{t+1}, s_{t+1}=s\right)\right]
$$

\subsection{Budget Constraints and Evolution of Cash on Hand}

Prior to retirement (at $t=K=43$ ), available financial resources $X_{t}$ are allocated across consumption, $C_{t}$, investment in stocks, $S_{t}$, investment in risk-free bonds, $B_{t}$, and IRA contributions, $A_{t}$. After retirement, additional IRA contributions are not possible, so the budget constraint is:

$$
X_{t}= \begin{cases}C_{t}+S_{t}+B_{t}+A_{t} & \text { for } t<K \\ C_{t}+S_{t}+B_{t} & \text { for } t \geq K\end{cases}
$$

Next period's cash on hand before, at, and after retirement evolves as follows:

$$
\begin{aligned}
& X_{t+1}= \\
& \begin{cases}Y_{t}\left(1-h_{t}\right)\left(1-c_{t}^{S S T}\right)+S_{t} R_{t+1}+B_{t} R_{f}-C G T_{t+1} & \text { for } t<K \\
\left(Y_{t}\left(1-h_{t}\right)+W_{L S}\right)\left(1-c_{t}^{S S T}\right)+S_{t} R_{t+1}+B_{t} R_{f}-C G T_{t+1} & \text { for } t=K \\
\left(Y_{t}\left(1-h_{t}\right)+W_{t}\right)\left(1-c_{t}^{S S T}\right)+S_{t} R_{t+1}+B_{t} R_{f}-C G T_{t+1} & \text { for } K<t \leq K+17 \\
\left(Y_{t}\left(1-h_{t}\right)+D\right)\left(1-c_{t}^{S S T}\right)+S_{t} R_{t+1}+B_{t} R_{f}-C G T_{t+1} & \text { for } t \geq K+18\end{cases}
\end{aligned}
$$

The first component of $X_{t+1}$ is gross income $Y_{t}$, either from work or from statutory pension benefits after retirement. Gross income is reduced by federal income taxes and required social security contributions (including unemployment insurance, health benefits, and state

\footnotetext{
${ }^{14}$ Hubener et al. (2016) use this approach to model transitions across family states.
} 
pensions), jointly levied as an average deduction rate $c_{t}^{S S T}$. This formulation reflects the detailed rules and parameters of the German social security system as well as the progressive income tax code. ${ }^{15}$ The average deduction rate is a function of gross income and whether someone is employed (equivalently, if time $t<K=43$ ), or retired. We apply the rules and parameters as of 2014 to generate values for $c_{t}^{S S T}$ between $10 \%$ for retirees with relatively low pension benefits and $44 \%$ for workers with salaries above $€ 150,000$. Following Gomes and Michaelides (2005), the resulting net income is further reduced by age-dependent housing costs, $h_{t}$, which we estimate using data from the German Socio-Economic Panel (SOEP). ${ }^{16}$

The second component of cash on hand is the market value of last year's investments in stocks and bonds including returns earned, $S_{t} R_{t+1}+B_{t} R_{f}$, less taxes on capital gains $C G T_{t+1}$. $R_{t+1}$ is the gross return on stocks which is assumed to be log-normally distributed, and $R_{f}$ is the risk-free return on bonds. Investment income from stocks and bonds is tax-exempt up to an annual limit of $€ 801$; in excess of this amount, a rate of $26.375 \%$ applies. After retirement, cash on hand includes lump sum withdrawals $W_{L S}$ (at age 67), withdrawals $W_{t}$ (from age 68 until 84 ) and constant nominal annuity payouts $D$ from the IRA (from age 85 onward), reduced by income taxes and contributions to health insurance.

In addition, each individual is posited to start the worklife with a given level of initial wealth, which we assume coincides with the worker's first simulated income level. Levels of starting wealth are estimated from the Deutsche Bundesbank's Panel on Household Finances (PHF) for individuals age $23-27 .{ }^{17}$ In calibrating capital market parameters, we use postGerman reunification data from June 1991 to December 2015; all calculations are carried out

\footnotetext{
${ }^{15}$ Online Appendix A provides additional detail on the German social security and income tax system.

${ }^{16}$ Additional details are provided in Online Appendix B. Property is the largest component of German household wealth (Deutsche Bundesbank, 2016), yet its purchase is generally accompanied by significant debt financing, violating our non-negativity assumption on asset holdings. For this reason we do not integrate housing decisions in the model and implicitly treat everyone as tenants. Panel A of Online Appendix B reports our estimated rental costs as a percentage of net income for the German population (estimated using SOEP).

${ }^{17}$ The values of starting wealth are $\{€ 0 ; € 140 ; € 515 ; € 1,250 ; € 2,300 ; € 3,980 ; € 7,300 ; € 12,300 ; € 17,180 ; € 40,300\}$.
} 
on a monthly basis and then annualized. All-item consumer prices are taken from Datastream; interest rate data refer to 1-year German government zerobonds taken from Deutsche Bundesbank; and equity data are from Datastream and refer to the largest German stock index, DAX 30.

For our 'base case' in the analysis below, we use sample means for all variables reflecting what had traditionally been seen as a 'normal' capital market environment. Specifically, the annual inflation rate $\pi$ is estimated at $1.75 \%$, close to the European Central Bank's (2018) inflation target of 'below, but close to, $2 \%$ over the medium term.' Mean nominal returns on government bonds $i_{f}$ are set at 3\%. The equity risk premium of the stock index is $6.83 \%$ with a volatility of $21.41 \%$; we downward-adjust the excess return to $6 \%$ in order to reflect management fees and trading costs. Both estimates are consistent with international and German historical risk premiums, as documented by Jordà et al. (2019).

\subsection{Labor Earnings and Retirement Income}

To model labor income, most life cycle studies adapt the methodology of Carroll and Samwick (1997), where earnings are a function of a deterministic trend component as well as permanent and transitory shocks (e.g. Cocco et al., 2005; Fagereng et al., 2017). By contrast, Fehr and Habermann (2008) discretized the labor income process to six levels (which they term productivity levels) with the transition path between the levels governed by a Markov transition matrix. In what follows, we combine both approaches, such that employees can migrate across $n_{s}=10$ income levels $f_{t, s}(s=1, \ldots, 10)$; we also add a transitory shock log-normally distributed as $\ln \left(U_{t, s}\right) \sim N\left(-0.5 \sigma_{\mathrm{u}, s}^{2}, \sigma_{\mathrm{u}, \mathrm{s}}^{2}\right)$. This approach retains the essence of Carroll and Samwick’s (1997) method while being computationally less burdensome. Consequently, during the worklife $(t<K)$, labor income $Y_{t}$ is the product of the age and state-dependent income level $f_{t, s}$ and the transitory shock $U_{t, s}$ such that: 


$$
Y_{t, s}=f_{t, s} U_{t, s}
$$

We calibrate the labor income process based on SOEP data. ${ }^{18}$ After retirement at age 67 , individuals in our model receive constant (real) lifelong benefits from the statutory pension system. These benefits are based on individual labor earnings (up to a ceiling) relative to population average labor income each year during the worklife. Given 2014 values for the contribution ceiling (of $€ 71,400$ ) and mean income (of $€ 34,514$ ), an annual maximum of $\frac{71,400}{34,514}=2.0687$ pension points can be earned. The sum of pension points earned is then multiplied by a 'pension value factor' (of €343.3) to determine annual pension income. ${ }^{19}$

\subsection{Structure of the Riester IRA}

Each period during the worklife, the employee decides on the amount contributed to the IRA, $A_{t}$. In addition, the government contributes an amount $b_{t}$ that includes the basic subsidy of up to $€ 175$, plus subsidies of up to $€ 300$ per child. In the model, we treat the number of children as deterministic and estimate the count of dependents using SOEP data. ${ }^{20}$ Two requirements must be fulfilled to be eligible to receive the maximum possible subsidy of $b^{\max }=175+300 \cdot n_{\text {children }}$. First, the worker must pay in at least $€ 60$ of own contributions to receive any IRA subsidy at all, i.e. $A_{t} \geq 60$. Second, the sum of the worker's own contribution $A_{t}$ plus the government's subsidy $b_{t}$ must equal the lesser of $4 \%$ of last year's annual gross income $Y_{t-1}$ or $€ 2,100$ (formally, $A_{t}+b_{t} \geq \min \left(0.04 \cdot Y_{t-1}, 2100\right)$ ). Lower IRA payments proportionally reduce the subsidies. Consequently, the fraction $\left(0 \leq \alpha_{t} \leq 1\right)$ of the maximum attainable subsidy granted is given by $\left(A_{t} \geq 60\right)$ :

\footnotetext{
${ }^{18}$ For details on the estimation and results see Online Appendix C.

${ }^{19}$ We use the same number of $n_{s}$ retirement income levels as for labor income, but once the pension state has been set, it remains indefinitely. Numerical values of each level's mean pension points and benefits (and boundaries between levels) are derived by simulating the income process prior to the optimization.

${ }^{20}$ Receipt of Riester child subsidies is contingent on entitlement to governmental child-care allowances, not reported in the SOEP. Instead we use the number of children living with parents as a proxy. Panel B of Online Appendix B reports our estimated numbers of children by age in the population.
} 


$$
\alpha_{t}=\max \left(\frac{A_{t}}{\min \left(0.04 \cdot Y_{t-1}, 2100\right)-b^{\max }}, 1\right)
$$

and the resulting subsidy paid into the IRA is:

$$
b_{t}=\alpha_{t} \cdot b^{\max }
$$

During the worklife, our model assumes that IRA assets are fully invested in stocks, and the product provider purchases at-the-money put options to hedge the money-back guarantee. Put premiums $P_{t}$ are directly charged from contributions, determined using the Black and Scholes (1973) formula. In addition, front-end loads may be paid out of contributions, but in our base case analysis, we set fees $\zeta$ to $0 \%$. Consistent with Gomes et al. (2009) our model rules out the possibility of withdrawals from the IRA before retirement due to high penalties which render this option unattractive. ${ }^{21}$

IRA contributions cease at the age of $66(t=K-1=42)$. If the plan balance at that time has fallen below the worker's lifetime sum of contributions and government subsidies, the product provider must top up the account by paying the difference $\Upsilon=\max \left(\sum_{t=1}^{K-1}\left(A_{t}+b_{t}\right)-\right.$ $\left.\operatorname{IR} A_{K}, 0\right)$. Subsequently, the saver may elect to withdraw up to $30 \%$ of the IRA value as a lump sum, $W_{L S}$. From the remaining balance, an assumed share of $20 \%$ is spent to purchase a deferred annuity that provides lifelong, nominally-fixed benefits of $D$ from age 85 onward. In pricing the deferred life annuity, we assume the discount rate corresponds to the assumed bond return; we also apply a population mortality table and add a markup of $12.5 \%$ to the respective annuity factor to reflect average loadings observed in the German private annuity market (Kaschützke and Maurer, 2011).22

\footnotetext{
${ }^{21}$ Early withdrawals of any amount trigger an immediate repayment of all granted subsidies and tax allowances. Given the average government grant of $38.2 \%$ per contribution (BMF, 2019) we assume that early withdrawals are largely unattractive (as especially liquidity constrained low earners receive the highest grant rates). Technically, allowing for early withdrawals would require to also track the sum of received tax allowances, what would cost an additional state variable. Penalty-free early withdrawals are feasible to purchase or construct owneroccupied property, yet housing decisions are beyond the scope of the model.

${ }^{22}$ The European Union Directive 2004/113/EC provides that men and women must be treated equally when calculating insurance premiums, so we compute annuity prices based on a unisex mortality table.
} 
Annual withdrawals of IRA assets from age $68(t=K+1)$ until age $84(t=K+17)$ are governed by the formula $W_{t}=\frac{I R A_{t}}{85-a g e_{t}}$, which implies that an increasing fraction of the remaining balance is withdrawn and full depletion of the account occurs at age 84 . The government also requires that benefits during the payout phase may not decrease. Since the provider must make up shortfalls with its equity capital, the portfolio allocation is shifted to a mix of $20 \%$ equity and $80 \%$ bonds during the payout phase. Therefore, the evolution of the IRA balance is given by:

$$
I R A_{t}= \begin{cases}\operatorname{IR} A_{t-1} \cdot R_{t}+\left(A_{t}+b_{t}\right)(1-\zeta)-P_{t} & \text { for } t<K \\ \left(\operatorname{IRA} A_{t-1} \cdot R_{t}+\Upsilon\right) \cdot 0.8-W_{L S} & \text { for } t=K \\ \operatorname{IR} A_{t-1} \cdot\left(0.2 \cdot R_{t}+0.8 \cdot R_{f}\right)-W_{t} & \text { for } K<t \leq K+17 \\ 0 & \text { for } t>K+17\end{cases}
$$

\subsection{Calibration and Numerical Solution}

We use dynamic stochastic programming to recursively solve the individual's optimization problem by backward induction. Derived policies govern how to behave optimally so as to maximize the present value of utility from today's and future consumption. During retirement, for all specifications, the model includes four state variables: cash on hand $\left(X_{t}\right)$, the IRA balance $\left(I R A_{t}\right)$, payouts from the deferred annuity $(D)$, and the retirement income state $(s)$. The state space is discretized using a $30(X) \times 20(I R A) \times 10(D) \times 10(s)$ grid size with equal spacing in the natural logarithm (measured in $€ 1,000)$ for the three continuous state variables $(X, I R A, D)$. During the worklife and with the IRA investment guarantee, the state of the deferred annuity is replaced by an equal number of grid points tracking the sum of guaranteed contributions and subsidies $\left(G_{t}\right)$, leaving the number of optimizations per time step unaltered at 60,000 . In the absence of a guarantee, this state can be saved which decreases the problem size by a factor of 10 . For each grid point, we calculate the optimal policies and value functions $\mathbb{E}_{t}\left[J_{t+1}(\cdot)\right]$ using Gauss-Hermite quadrature integration and cubic spline interpolation. In the subsequent simulation, 100,000 independent life cycles are generated using optimal feedback controls. 
In a matching procedure closely related to Love (2010), we select preference parameters such that the model generates average asset holdings consistent with empirical evidence derived from the Deutsche Bundesbank's PHF. Specifically, the discount factor $\beta$ and the coefficient of relative risk aversion $\gamma$ are chosen in model calibration such that the sum of relative squared differences between average model wealth and the empirical data is minimized using five-year age groups. The best fit is achieved with a discount factor of $\beta=0.93$ and relative risk aversion of $\gamma=7 .^{23}$

\section{Results}

Next we illustrate the implications of switching from the money-back guaranteed IRA to an otherwise identical retirement account without the guarantee. In particular, we show how eliminating the guarantee in the above model alters a utility-maximizing individual's optimal contributions to the IRA during the worklife, IRA payouts during retirement, liquid asset holdings, and consumption opportunities over the life cycle. Our base case calibration assumes a nominal risk-free rate of $3 \%$ and an inflation rate of $1.75 \%$, while the alternative low return scenario posits a $0 \%$ interest and inflation rate. These alternatives highlight the protective role of the guarantee as well as its negative consequences for consumption.

Figure 1 shows how pre-tax earnings, liquid asset holdings (stock and bonds), IRA contributions, balances, and payouts evolve, along with optimal non-housing consumption ${ }^{24}$ for a money-back guarantee IRA (Panel A) versus an IRA without a guarantee (Panel B) in the base case. ${ }^{25}$ In both scenarios, consumption is slightly hump-shaped. Rising consumption during the first decade of the worklife results from the well-known effect of constrained borrowing given rising labor income (Chai et al., 2011). Falling consumption during retirement

\footnotetext{
${ }^{23}$ A description of the methodology and visualizations of model-generated and empirical data for the eight age groups appear in Online Appendix D.

${ }^{24}$ In the following, we use the terms 'non-housing consumption' and 'consumption' interchangeably.

${ }^{25}$ All values are expressed in $€ 2015$.
} 
is mainly driven by the interaction of a relatively low subjective discount factor and rising mortality probabilities that reduces the demand for consumption smoothing. It is notable that consumption during the worklife is significantly below pre-tax labor income, mainly due to income taxes, social security contributions, housing costs, and to a lesser extent, savings. For example, at age 50, labor income peaks and workers earn, on average, about $€ 39,600$. Out of that income, $€ 14,550$ is spent on social security, income taxes, and capital gains taxes; $€ 7,850$ on housing expenses; $€ 16,350$ on consumption; and only $€ 850$ is devoted to savings, mostly using tax-qualified IRAs.

Figure 1 here

Panel A of Figure 1 shows that, with a guarantee at age 67, the IRA is reduced by about $€ 38,300$, to $€ 75,400$. This is because, first, the product provider expends $20 \%(€ 22,400)$ of the account balance to purchase an annuity with benefits being deferred until age 85 . Second, the retiree withdraws about $€ 15,900$ (or $14.5 \%$ ) of the IRA balance as a lump sum at that point. This is well below the allowed maximum of $30 \%$, enabling the retiree to enjoy higher withdrawals later in life. Of this lump sum payout, about one third (35\%) goes to income taxes, and another $50 \%$ is used to support consumption. The remaining $15 \%$ is shifted into nonqualified liquid assets which offer greater flexibility in asset allocation and timing of cash flows than the IRA.

At age 68, the saver's income consists of $€ 15,450$ from the social insurance system, $€ 4,550$ from the IRA withdrawal plan, and she sells $€ 5,050$ of stocks and bonds. After taxes and social security payments, $€ 3,950$ is spent on housing and $€ 16,200$ on non-housing consumption. Of these expenses, $60 \%$ are covered by public pension benefits, $18 \%$ from IRA payouts, and $22 \%$ from liquidating stock and bond holdings. In later periods, consumption smoothing allows the individual to reduce the sale of stocks and bonds when expected payouts from the IRA increase. At age 85 , her IRA payouts consist only of constant nominal annuity payments. By then, the share of income from the social insurance program has risen to $67 \%$, 
IRA annuity payouts to $27 \%$, and stock and bond sales only amount to $6 \%$. After age 85 , consumption decreases because annuity payouts are devalued by inflation and liquid assets have fallen to levels inadequate to maintain previous consumption levels (e.g. at age 85 stock and bond sales amount to only €500).

Next we compare consumption, income, and asset holding patterns for the no guarantee case, depicted in Panel B. While most of the results are similar, one difference is the $11 \%$ higher average IRA balance of $€ 125,600$ without the guarantee at retirement, versus $€ 113,650$ with the guarantee. Greater IRA saving results partly from lower liquid savings: by retirement, these are crowded out by about $7.2 \%$ (to only $€ 34,200$ ). ${ }^{26}$ Additionally, a higher share of consumption is financed by IRA distributions without the guarantee, versus with it (21\% vs. $18 \%$ at age 67 , $41 \%$ vs. $27 \%$ at age 85$)$.

Differences in IRA balances may be attributed to paying hedging costs with a moneyback guarantee, as well as to differences in contributions across the two scenarios. Figure 2 provides a more detailed picture of optimal IRA contribution patterns over the life cycle, again with and without investment guarantees. Panel A shows the share of individuals with positive contributions to the IRA, where results are similar under the two scenarios. Starting from low figures in the range of $20 \%$ to $25 \%$, the participation rate gradually rises to $60 \%$ at age 40 , and then it flattens out. The lower participation rate by young workers is driven by relatively low (but rising) labor incomes and households' need to build up precautionary liquid savings before engaging in illiquid retirement saving. Panel B depicts average IRA contribution rates (including subsidies) as share of gross income, conditional on participation. Here contribution rates are hump-shaped, rising from $2.5-3.0 \%$ in the twenties to a peak of $4 \%$ at age 49 , falling

\footnotetext{
${ }^{26}$ The first two columns of Table 5 summarize the data for the total population and IRAs with (without) moneyback guarantee. A breakdown by income classes is provided in Table 2 .
} 
thereafter to $1.8-2.6 \%$ after age 60 . The model-determined falling contribution rates in later life are due to the fact that the appeal of tax deferral declines as retirement approaches. ${ }^{27}$

\section{Figure 2 here}

Beyond age 55, Panel B of Figure 2 shows that participation and contribution rates are systematically higher without the guarantee. Two factors drive this result. First, for the guaranteed IRA, the cost of purchasing put options becomes more relevant with less time to maturity, leading people to optimally reduce contributions as they near retirement. Second, IRA participants without the guarantee who experience unfavorable returns late in their work lives will optimally increase contributions to offset losses. Ultimately, different guarantee costs and payouts, IRA contributions and withdrawals, and portfolio allocations, jointly translate into consumption differences.

For our base calibration, the fan chart in the top panel of Figure 3 depicts path-wise percentage consumption differences without versus with the guarantee, where the IRA with a guarantee is the reference. The turquoise line in the top panel depicts the mean consumption difference, while the blue surface illustrates the $5^{\text {th }}$ to $95^{\text {th }}$ percentile with shading being proportional to the distribution mass. The bottom panel reports the share of people having higher consumption in the absence of a guarantee. Overall, mean consumption differences are positive in all periods (except the first), and the dispersion increases with age. Until age 50, consumption is virtually the same with or without the IRA money-back guarantee. In retirement, higher account balances in the no guarantee case result in larger plan withdrawals and annuity payouts that improve old-age consumption considerably. Importantly, consumption is enhanced most when it is at its lowest levels, and the marginal utility of consumption is highest. Put differently, eliminating the guarantee reduces the impact of longevity risk most,

\footnotetext{
${ }^{27}$ The hump-shaped contribution pattern generated by our model is largely in line with actual contribution patterns reported by Dolls et al. (2018), though they show contributions peaking about five years earlier.
} 
just when unanticipated spending needs might not be met due to low levels of liquid assets and binding borrowing constraints.

\section{Figure 3 here}

The bottom panel of Figure 3 shows that most people would be advantaged if their retirement accounts had no guarantee. By retirement age, for instance, three-quarters of all individuals would be better off without the IRA guarantee, and by the end of their lives, this percentage rises to $91 \%$. This is because higher withdrawals improve consumption opportunities, and larger annuity payouts supplement social insurance program benefits after liquid assets are depleted. The bottom panel shows only the frequency of individuals who have higher consumption without the IRA guarantee, while the shaded areas in the top panel quantify the magnitudes of the changes. Overall, the distribution around the turquoise mean line is fairly symmetric, implying that even those who are protected by the guarantee benefit relatively little. For instance, the largest protection offered by the guarantee occurs at age 67 , when consumption with a guarantee on the $5^{\text {th }}$ percentile would be $3.2 \%$ higher for those with poor capital market experiences. At the same age, those with positive capital market experiences at the $95^{\text {th }}$ percentile could boost their consumption by over $4.8 \%$, if the IRA had no guarantee. Until the terminal period, the level of protection provided tends to decrease, while excess consumption rises from abolishing the guarantee. For instance, at age 95 , those in the $5^{\text {th }}$ percentile who have the guarantee only receive $1.6 \%$ more consumption. Conversely, those at the $95^{\text {th }}$ percentile would expect $9.8 \%$ higher consumption if the IRA had no guarantee. In other words, the upside exceeds the downside in terms of consumption from switching to an IRA regime without a guarantee.

Table 2 examines whether the implications of switching to a non-guaranteed IRA differ by workers' income group. In our base calibration, Panels A to D report consumption, liquid savings, IRA balances, and payouts (in $€ 1,000$ ) for the bottom, middle, and top $10 \%$ of lifetime income observations. Panel E quantifies the share of retiree consumption and housing costs that 
can be financed by IRA payouts, while Panel F reports the frequency of simulated life cycles in which the IRA balance at retirement falls short of the guaranteed amount (both in \%). The columns labeled 'With' show average amounts by age groups for the IRA regime including a money-back guarantee; the columns labeled 'Without' report results for a no-guarantee regime. Results are presented as a percentage of the respective guarantee counterfactual.

\section{Table 2 here}

A key lesson from Panel A is that average consumption is similar in the early years, but without a guarantee, consumption for all three income groups increases monotonically, rising to an annual $2-4 \%$ more for the no-guarantee IRA over the last 20 years of life. These improvements are larger in percentage terms for top and middle income earners who can afford higher IRA contributions, yet a 3\% improvement for low income earners is still important given their high marginal utility of consumption. We also find that IRAs without guarantees crowd out liquid savings (see Panel B). The reason is that higher average IRA payouts in retirement permit an individual to draw down liquid savings earlier, because the higher annuity payouts are sufficient to reduce longevity risk. This reduction in liquid assets is most notable for middle and low earners, both of whom reduce their liquid savings by $8-10 \%$ from age 60 to 79 . By contrast, workers earning the highest incomes reduce their liquid assets by only $3 \%$. This complements the result in Panel C that IRA balances are higher for all income groups without the guarantee, and those with low earnings boost their IRA balances the most.

Another finding is that the higher level of IRA assets accrued by low income earners age $60-79$ is $+22 \%$, without versus with a guarantee; top $10 \%$ earners accumulate only $+9 \%$ more. As shown in Panel E of Table 2, the relative importance of IRA savings to fund old-age consumption for wealthier individuals exceeds that of the less wealthy. Hence the impact of potential losses from adverse capital market returns on consumption is much greater for higher paid workers. Accordingly, lower earners benefit more from a non-money-back IRA, compared to the high income earners. 
Panel D summarizes the IRA payouts which mirror results in prior Panels. For the top (middle) earners, non-guaranteed IRA payouts are 9\% (11\%) higher than with guarantees; for low earners, IRA payouts rise by $21-22 \%$. This large improvement for the lowest earners provides only a $2-3 \%$ total consumption increase, as their IRA balances and liquid assets are still low. ${ }^{28}$ Panel $\mathrm{F}$ quantifies the downside risk of switching from a guaranteed to a nonguaranteed IRA regime for each of the three income groups. By construction, for scenarios with money-back guarantees, there is no shortfall risk (defined as having an IRA balance at retirement below the sum of contributions and subsidies). Even without a guarantee, the shortfall probability for high and middle income earners is moderate, at $3.9 \%$ and $5.7 \%$, respectively. Yet for low earners, the shortfall probability is much higher, at $11.5 \%$. This difference can be attributed to the fact that low income earners tend to contribute considerably later, around age 57.8, versus age 49,1 for high and 51.1 for middle income earners. Forgoing early contributions implies that the low earners build only a small cushion against adverse capital market developments, and therefore they are more vulnerable to losses later in life.

Though low earners experience the least additional consumption and are exposed to the increase in shortfall risk without guarantees, Table 3 reveals that the proportion of these individuals better off without the guarantee is the largest: from ages $60-79,72 \%$ are better off, and $89 \%$ between the ages of $80-100$. The proportions are similar for middle earners, at $75 \%$ and $88 \%$, respectively. Among the highest earners, the majority is better off: $68 \%$ (81\%) of this group enjoys more consumption between ages 60-79 (ages 80-100).

\section{Table 3 here}

It is also of interest to compare IRA participation rates, which we do in Table 4. Here we see that, for all income and age groups, the share of workers contributing to an IRA is at least

\footnotetext{
${ }^{28}$ Bonin (2009) and Börsch-Supan et al. (2008) note that low income households may find it unattractive to save in pension products due to high current consumption utility, and tax incentives tend to be weaker than for their wealthier counterparts.
} 
as high without as with a guarantee. Nevertheless, high earners follow a hump-shaped participation pattern over their life cycles. Middle income earners trace out a flat trajectory, and participation for low earners is low during their early and middle years and rises only near retirement.

\section{Table 4 here}

The first two columns of Table 5 provide the same information as Table 2, but now we average results over the entire population instead of by income subgroups. Results for a real guarantee (columns 3 and 6) are discussed below, in the robustness check section. Columns 4 and 5 at the aggregate level show results for the alternative capital market environment with interest and inflation rates of $0 \%$. Here it is clear that the negative implications of the mandatory money-back guarantee are amplified, which we ascribe to the disproportionately higher costs of providing the guarantee. Table 5 also reveals that IRA balances (Panel C) and payouts (Panel D) during retirement plummet by around two-thirds (63-67\%) under the zero interest rate regime. By contrast, liquid savings rise by over $45 \%$ as of the retirement date (Panel B). Nevertheless, the higher liquid savings are insufficient to fully compensate for lower IRA payouts, so old-age consumption (Panel A) falls in the low return scenario by around $9 \%$ compared to the historically 'normal' environment. Importantly, the relative advantage of abolishing the guarantee in terms of old-age consumption rises substantially from $3 \%$ to $11 \%$ of retiree consumption, versus the normal capital market scenario. In other words, eliminating the money-back guarantee would substantially benefit retirees in the current low return environment.

\section{Table 5 here}

Figure 4 provides insights into the heterogeneous changes in contributions and retiree consumption by average annual income, without versus with the guarantee. The $\mathrm{x}$-axis shows average yearly lifetime labor income, while the y-axis displays the change in IRA contributions 
(including subsidies, expressed as percent of lifetime labor income) if the IRA's investment guarantee were eliminated. Each of the 100,000 circles indicates how much individuals would gain or lose from abolishing the money-back guarantee. Green (purple) circles depict increases (decreases) in average yearly retirement consumption, and darker color circles reflect larger changes (white circles indicate small or zero changes).

\section{Figure 4 here}

For the base case calibration with historically normal interest and inflation rates, Panel A indicates that most participants (about 71.5\%) increase their contributions without the guarantee. Moreover, the dispersion in contribution changes is wider for high versus low earners. Consistent with the bottom Panel of Figure 3, green circles dominate, so most retirees enjoy greater consumption without the guarantee. Those benefitting from elimination of the guarantee also boost their contributions, except for some low income workers whose anticipated consumption rises so they therefore can cut back on contributions. The circle colors indicate that those who neither gain nor lose from the IRA guarantee status predominate among workers who cut their contributions. Importantly, while average retiree consumption is unaffected, eliminating the guarantee still leaves workers with higher consumption during the accumulation phase. Moreover, those experiencing reduced old-age consumption are mainly high-income earners. As shown in Table 2, the relative importance of IRA savings to fund old-age consumption for wealthier individuals exceeds that of the less wealthy. Consequently, without the IRA money-back guarantee, the wealthy become more vulnerable to negative capital market experiences late in life, compared to their less wealthy counterparts.

Panel B of Figure 4 emphasizes that, in the low return environment, the IRA guarantee has two offsetting impacts. On the one hand, retiree consumption rises most without the guarantee - by an average of $6.7 \%$ - indicated by dark green circles which clearly outnumber the dark purple circles. On the other hand, more participants enjoy significant protection from a guarantee when a low return environment prevails. 
In the low return environment, several important differences should be noted. First, most participants who benefit from abolishing the guarantee (green circles) cut their lifetime contributions. Of those, a second clustering of low income earners can be observed; for them, the vast majority enjoys significant consumption improvements. There is even more heterogeneity in consumption at the top of the income distribution. Again, this can be attributed to the higher earner's greater exposure to poor capital market shocks toward the end of the accumulation period. The clustering of high income earners having large consumption losses and making higher contributions (top right of Panel B) are those who experienced large IRA losses in the decade prior to retirement. To regain IRA wealth sufficient to support old-age consumption, their contributions rise sharply to about $5 \%$ of income (about 2.5 times the population average).

Overall, this Section has shown that eliminating the IRA guarantee enhances average consumption opportunities for savers, particularly for middle and higher earners, because the guarantee costs outweigh the benefits of downside protection. Moreover, people save more in their non-guaranteed IRAs compared to the guaranteed IRA, allowing them to reduce their liquid stock and bond holdings. This conclusion is sharpened in a low return/inflation scenario, though more people will suffer losses when not covered by the IRA guarantee. Since significant losses can occur for savers without a guarantee, this raises the question as to whether a life cycle investment strategy such as a target date fund might be an attractive alternative. We examine this option below.

\section{Robustness Checks}

Having investigated the economic implications of a money-back nominal IRA guarantee on plan participant behavior, we next confirm that an inflation-protected guarantee would amplify the concerns already raised for nominal guarantees. And importantly, we show that a life cycle or target date strategy with insufficient equity exposure can be even less attractive 
than a money-back IRA guarantee. Finally, even for scenarios when equity market crashes happen during the last working period, we find that plans without a guarantee perform surprisingly well. ${ }^{29,30}$

\subsection{Real Guarantees}

Thus far, we have taken as given the regulation requiring a nominal money-back guarantee at the end of the accumulation phase. Nevertheless, some authors have explored inflation protection over the guarantee contract's term. ${ }^{31}$ The appeal of a real guarantee is that it preserves savers' purchasing power, though it requires higher costs and therefore can erode account balances over time. For instance, Pennacchi (1999) and Fischer (1999) discussed the Latin American pension market where real guarantees were promised during times of high inflation: there the guarantees were usually not market-based (replicated by combining tradeable assets) but instead were provided by governments.

To illustrate how an inflation-protected guarantee might work in our context, we replace the nominal with a real money-back guarantee. ${ }^{32}$ To this end, instead of buying at-the-money put options with the contributions, in-the-money put options must be purchased with strike prices accounting for inflation accruing until retirement. Results for the base calibration in Column 3 of Table 5 support our conjecture that real guarantees erode consumption even more than nominal guarantees. ${ }^{33}$

\section{Table 5 here}

\footnotetext{
${ }^{29}$ In Online Appendix E we demonstrate that our results are also robust to using Epstein-Zin-Weil preferences, and that demand for the IRA is only moderately affected by introduction of common front-end loads $\zeta$ of $5 \%$ on IRA contributions.

${ }^{30}$ In Online Appendix F we show that the conclusions are not a result of uniquely German circumstances, but that they also hold for a more generalized IRA setup.

${ }^{31}$ For instance, Feldstein and Samwick (2002) and Feldstein (2009) considered real guarantees for investmentbased Social Security reforms in the U.S.

${ }^{32}$ We keep the annuity payouts as nominal to maintain consistency with previous analyses.

${ }^{33}$ For the zero inflation scenario in Column 6 of Table 5, results correspond to those of the nominal guarantee in Column 4.
} 
Specifically, old-age consumption under a real guarantee falls short of the nominal guarantee scheme by 2 to $6 \%$ on average (Panel A). The average timing and the sum of contributions is very similar across guarantee designs, so the approximately $16 \%$ decline in account balances and payouts may be directly attributed to higher guarantee costs (Panels C and D). To compensate for lower IRA payouts under a real guarantee, liquid saving increases beyond the levels in the other two cases. Our analysis shows that a real guarantee compounds the negative effects of nominal guarantees.

\subsection{Life Cycle Target Date Funds}

Some might argue that life cycle or target date funds could constitute a viable alternative to money-back guarantees as a risk mitigation technique. This type of investment approach follows an age-based allocation rule, starting with higher equity shares early in life, and gradually rebalancing along a glide path to less risky securities (such as bonds) near and into retirement (Vanguard, 2017). In the U.S., much of the $\$ 5$ trillion invested in 401(k) defined contribution retirement plans is automatically defaulted into target date investment strategies. ${ }^{34}$ The regulatory environment for the European Union's Basic PEPP also allows providers to use a life cycle strategy, under the presumption that it is 'consistent with the objective of allowing the PEPP saver to recoup the capital' instead of requiring a money-back guarantee (see EU 2019/1238 (54) and Art. 46).

While there are many variants of life cycle strategies in the market, two general approaches are common. ${ }^{35}$ One starts investors at a relatively high equity exposure and reduces this share annually using a moderate adjustment factor. For example, Malkiel (1996) postulated that the percentage of IRA assets invested in equities should follow a ' 100 - age' rule. A second approach retains a high equity exposure during much of the accumulation period, but imposes

\footnotetext{
${ }^{34}$ The U.S. legislative framework has encouraged this practice, with the 2006 Pension Protection Act permitting plan sponsors to include target date funds as 'qualified default investment alternatives'.

${ }^{35}$ For an overview, see Poterba et al. (2006) and Berardi et al. (2018). Gomes et al. (2020b) showed that target date fund returns can be improved by following simple heuristics that exploit stock market predictability.
} 
a stronger de-risking pattern near retirement. Cocco et al. (2005) proposed reducing the $100 \%$ equity exposure from age 41 onwards by 2.5 percentage points per year until retirement (hereafter referred to as ' 100 -until-40, -2.5 ' rule), which is largely consistent with flat equity shares until age 40 that decrease almost linearly to about $40 \%$ before retirement common in U.S. target date funds (van Bilsen et al., 2020). Using a simulation approach, Berardi et al. (2018) studied a range of other life cycle approaches, finding that the value of contributions can be preserved with over $99 \%$ probability given an intermediate investment horizon of 40 years; with a $95 \%$ probability, the final account balance is likely to be worth at least 1.8 times the sum of contributions. While these results suggest that a life cycle approach could be appealing from a shortfall perspective, it has not yet been demonstrated whether decreasing the risky share is preferable to a money-back guarantee.

Accordingly, we extend our analyses by introducing the two life cycle approaches sketched above, where the IRA's equity share during the participant's worklife is set either using a '100 - age' rule, or a '100-until-40, -2.5 ' rule. The remainder of the portfolio is then invested in risk-free bonds. To maintain consistency with the previous setup, we assume that the IRA switches to a 20\% equity exposure after retirement. Results appear in Tables 6 and 7, for the base 'normal' case, as well as the low interest rate and inflation scenario.

\section{Tables 6 and 7 here}

For the 3\% nominal interest base case, Panel A of Table 6 depicts old-age consumption when the IRA invests in a ' 100 minus age' life cycle fund; this proves to be some $5-15 \%$ below that achieved in the guarantee case. Panel A of Table 7 indicates that, during retirement, twothirds of plan participants can consume more if they have a guaranteed IRA compared to the more conservative life cycle fund. This is because people accumulate about one-third less in their IRAs with the conservative life cycle fund, compared to the guarantee case (Panel C, Table 
6). ${ }^{36}$ As a result, also the share of consumption financed by IRA payouts is $7-10$ percentage points lower than that resulting from a $100 \%$ equity exposure with a money-back guarantee.

This highlights the fact that the life cycle glide path reduces the equity share too quickly during the accumulation phase so asset accumulation is hampered - even with higher contributions - and less capital can be withdrawn during the payout phase (Panel D, Table 6). Although this disadvantage is partly mitigated by the alternative life cycle rule ('100-until-40, $\left.-2.5^{\prime}\right)$, it is not eliminated. Panel F of Table 6 confirms Berardi et al.'s (2018) finding that, in a normal capital market scenario, shortfalls are rare when the IRA is invested in a life cycle fund, occurring in only $0.9 \%(1.3 \%)$ of the cases for the '100 minus age' rule (' $100-$ until-40, -2.5 ' rule) versus the $6.4 \%$ shortfall probability without a guarantee. ${ }^{37}$

Next we explore how results differ in a less propitious capital market environment. As noted above, costs for money-back guarantees become more expensive, due to higher put premiums. Also the larger share of bonds in the life cycle strategy produces lower returns. Compared to the IRA guarantee case, expected old-age consumption in Table 6 with the conservative ('100 minus age') target date fund falls short by only $1-2 \%$ (Panel A), and the share of consumption (including housing) financed by IRA payouts is only $0.5-0.8$ percentage points lower (Panel E). Panel B of Table 7 shows that less than half (43-44\%) of retirees anticipate consuming more with the life cycle fund in their IRAs, yet the shortfall probability (Panel F of Table 6) increases substantially to $18.7 \%$.

By contrast, in the zero interest rate scenario, the ' $100-$ until-40, -2.5 ' fund holding more equity can partly overcome the burden of a high bond allocation during the accumulation phase. Compared to the money-back IRA, this more aggressive life cycle approach provides $1-2 \%$

\footnotetext{
${ }^{36}$ Interestingly, the lower IRA balances are not driven by lower contributions: in fact, the sum of contributions is the highest for the ' 100 minus age' life cycle fund case, averaging $€ 27,300$, followed by the no guarantee case $(€ 23,150)$, and the guarantee case last $(€ 22,400)$.

${ }^{37}$ We note, however, that Berardi et al. (2018) have a money-weighted timing of contributions in the middle of the accumulation phase, while in our case it is about five years later (after 26.2 years); ours provides less time for compounding. Moreover, around half of their bond investments consist of credit-risky bonds, enabling their portfolios to benefit from a risk premium.
} 
more old-age consumption (Panel A, Table 6). Moreover about 55\% of retirees can expect to consume more (Panel B, Table 7), and the share of expenditures in old-age financed by IRA payouts increases by $1.2-1.8$ percentage points (Panel E, Table 6). Nevertheless, the shortfall probability is high, at $17.6 \%$, a value inconsistent with the EU regulatory objective of 'recouping the capital' of the PEPP saver.

\subsection{Resilience to Capital Market Crashes}

The purpose of guarantees in IRAs is to offer downside protection against adverse capital market developments, although as we have shown, this comes at the cost of lower average payouts. Indeed, our results above suggest that guarantees do harm consumption and downside protection appears surprisingly small. Nevertheless, since savers choosing guaranteed IRAs seem to value the promised protection, next we quantify how well such IRAs might perform if a severe shock hit the equity market in the terminal period of the accumulation phase. In particular, we examine a scenario where the equity market unexpectedly plummets by $35 \%$ just before retirement. ${ }^{38}$

The histograms in Figure 5 report a metric we term the distance to guarantee payoff for an IRA having a guarantee, compared to alternative risk-mitigation techniques. This metric quantifies how big the equity return in the last work period would need to be, such that at retirement the IRA balance exactly matched the sum of contributions and subsidies (the guarantee amount).

\section{Figure 5 here}

For the low interest rate scenario, in the left Panel, the light (dark) bars show the frequency distribution of the distance to guarantee payoff for an IRA with (without) a moneyback guarantee. This is measured one year from retirement in all cases. The vertical line splits

\footnotetext{
${ }^{38}$ This equity market crash roughly corresponds to the decline of the German DAX index after the outbreak of the coronavirus in early 2020, which in the European context, was the first equity market crash in the era of zero or negative nominal interest rates. This also corresponds to the $4.4 \%$ quantile of the distribution of 12 -month rolling returns of the index since $06 / 1990$.
} 
the data into accounts in surplus over the guarantee amount (left of the line), and those in deficit (right of the line). With a guarantee, $46.2 \%$ of the guaranteed IRA balances fall short one year before retirement, whereas without a guarantee, only about one-fifth of the accounts are in shortfall $(22.3 \%)$.

Moreover, for the no-guarantee scenario, the probability mass is much more concentrated at the left side of the plot, where accounts deep in surplus are found. These have accumulated large cushions over the guarantee amount, enabling them to withstand even unusually large equity market crashes before balances fall below the guarantee amounts. Significantly smaller cushions are evident for the money-back guaranteed IRA, attributed to the costs of providing the guarantee (see Panel A of Table 2). These expenses constitute a drag on the investable capital that make it much more likely that a guarantee will eventually pay off.

The fan charts in Figure 5 illustrate path-wise consumption differences between the guaranteed IRA versus alternative risk-mitigation strategies, when the equity market unexpectedly plummets by $35 \%$ in the year prior to retirement. ${ }^{39}$ The right side of Panel A compares consumption and welfare under the no-guarantee IRA versus with the guarantee. Even after such a severe equity market crash, average retiree consumption without the guarantee would be about $1-7 \%$ higher, and $51-74 \%$ of the savers could consume more. Naturally, this comes at the cost of tolerating inferior downside measures for part of the return distribution. Yet even the least fortunate 5\% quantile of the distribution would not experience disastrous consumption losses (though losing 5 to $7 \%$ of retiree consumption is still considerable). It may be surprising to some that, even in this rare market crash scenario, a guarantee does not strictly dominate.

\footnotetext{
${ }^{39}$ Here, we focus only on losses occurring during the last work period, because there is no chance that the balance can recover before the money-back guarantee is tested. Losses occurring at other times during the accumulation phase are less of a concern as the test is applied only at age 67.
} 
Panels $\mathrm{B}$ and $\mathrm{C}$ evaluate life cycle funds as alternative risk-mitigation technique to money-back guarantees. Panel B implements the ' 100 minus age' rule, while Panel C implements the more risk tolerant ' $100-u n t i l-40,-2.5$ ' rule. One year prior to retirement, the derisking along the glide paths leaves the life cycle IRAs with equity exposures of only $34 \%$ and $35 \%$, respectively, and almost one-quarter of the IRAs could even withstand a $100 \%$ loss in the equity market without their balances falling below the sum of contributions and subsidies. It is worth noting, however, that the distributions are more evenly arrayed along the x-axis than in Panel A, so a year before retirement, the share of accounts with balances below the guarantee amount is significantly higher for the life cycle funds (at $42.3 \%$ in Panel B, and $37.6 \%$ in Panel C) than for the no-guarantee IRA, but lower than for the IRA embedding a guarantee.

Reasons that the life cycle funds can fall below the threshold include (i) locking in both surpluses and deficits early due to de-risking, and (ii) when the nominal interest rate equals $0 \%$, the bond investment does not contribute to building a cushion over the guarantee amount. Put differently, due to the early decline in the risky share, the life cycle IRAs forgo earning the risk premium to an extent that eventually makes shortfalls even more likely. In line with this, the fan charts reveal that even in an extremely negative capital market scenario, the no-guarantee IRA yields superior average consumption than the life cycle funds, but the downside is not much worse. Importantly, within life cycle funds, the more risk tolerant allocation (Panel C) does better on consumption and downside, as it allows the individual to retain more equity risk premium.

\section{Conclusions}

This study illustrates how money-back guarantees in individual retirement accounts can alter lifetime consumption opportunities and portfolio decisions. We build and calibrate a dynamic life cycle model where the saver in an IRA of the German Riester type has access to stocks, bonds, and IRAs, and we show that old-age consumption could rise substantially for 
most people if the money-back guarantee were eliminated. This is because removing the IRA guarantee saves money otherwise spent to provide the guarantee, which could instead be directly invested to the benefit of the saver.

During what many believed to be a 'normal' long-term capital market environment, with a 3\% nominal interest rate, we show that average retirement consumption could have risen by $2-4 \%$ if the IRA fully invested in equities had no guarantee. Moreover, three-quarters of savers could have consumed more early in retirement, rising to above $90 \%$ of retirees near the end of life. Accordingly, a money-back guarantee for an IRA is evidently not a cost-effective way to overcome longevity risk for the older population. Of course giving up the guarantee does expose participants to shortfall risks that must be weighed against the higher return potential. We show that switching to a non-guaranteed IRA would have been appealing overall, even though those experiencing extremely adverse capital market shocks could experience losses compared to the guarantee case.

In a persistent low interest rate environment, our results are more nuanced. It remains the case that average consumption would rise by $3-11 \%$ if the guarantee were removed, but the fraction of people experiencing shortfalls also increases to $18.1 \%$. Accordingly, examining heterogeneity in outcomes becomes important. Remarkably, the vast majority of low to middle lifetime earners are better served in terms of old-age consumption if they do not have the money-back guarantee; higher income savers benefit the most from the guarantee. Additionally, in a persistent low return scenario, industry providers may be unwilling to offer guaranteed IRAs if they must systematically run losses to make up for shortfalls not covered by hedging payoffs. Such obligations could eventually force IRA providers to abandon the market, which would be detrimental to the future of the funded private retirement system. If a real rather than a nominal investment guarantee were required, this would harm savers even more.

Against this background, we also investigated whether life cycle or target date funds could be considered to be a viable alternative to the money-back IRA guarantee approach. For 
example, the Pan-European Personal Pension Product includes such a strategy as a possible default investment option. Our results confirm that the appeal depends on the interest rate environment and the design of the glide path. In a normal interest rate environment, a life cycle fund results in less old-age consumption compared to the money-back approach. By contrast, in a low interest rate environment, life cycle funds can provide consumption comparable to that under the money-back guarantee scenario. For instance, a life cycle fund with a conservative equity exposure such as the traditional '100 minus age' rule, results in lower old-age consumption for both the normal and low interest rate scenarios. By contrast, a life cycle approach with a higher equity exposure maintained longer (e.g. reducing a 100\% equity after age 40 by 2.5 percentage points per year) can generate higher consumption.

We additionally show that, even under quite extreme stock market crash scenarios, IRAs without guarantees perform well compared to the alternatives. Thus if the market declined by $35 \%$ during the employee's last year of work, average consumption without a guarantee would still exceed that with a guarantee or a life cycle fund of the type examined here. This superior consumption can be attributed to deficiencies in the alternatives: the erosion of IRA assets due to guarantee costs in the money-back case, and the too-early risky share decline in life cycle funds.

In sum, our work confirms that money-back guarantees were an effective way to protect workers from investment losses in their IRAs during a 'normal' capital market environment. Unfortunately, now that interest rates are persistently low, the money-back guaranteed retirement account does not protect the saving public. Instead, the guarantee can cause unintended harm, by eroding old-age consumption below what it would be otherwise. Life cycle funds with sufficient equity exposure can be an alternative risk mitigation strategy, and we show these are preferable to a guaranteed IRA.

Our findings are relevant to policymakers, regulators, and plan sponsors globally, insofar as many countries are responding to the challenges of population aging by implementing funded 
individual retirement accounts. These include the U.S. 401(k) retirement accounts, the PEPP recently launched by the European Parliament, and defined contribution plans in Australia, Hong Kong, and Chile, along with many other countries. Of key importance in such funded pension systems is the appropriate design of default investment options which, on the one hand, protect savers from downside risks, while on the other hand, preserve the opportunity for savers to access the capital markets. In particular, regulators will benefit from a clearer understanding of the costs and benefits associated with money-back guarantees, as well as other risk mitigation techniques such as life cycle funds. 
Figure 1: Life Cycle Profiles With and Without IRA Guarantee: Base Case

\section{Panel A: With guarantee}

140

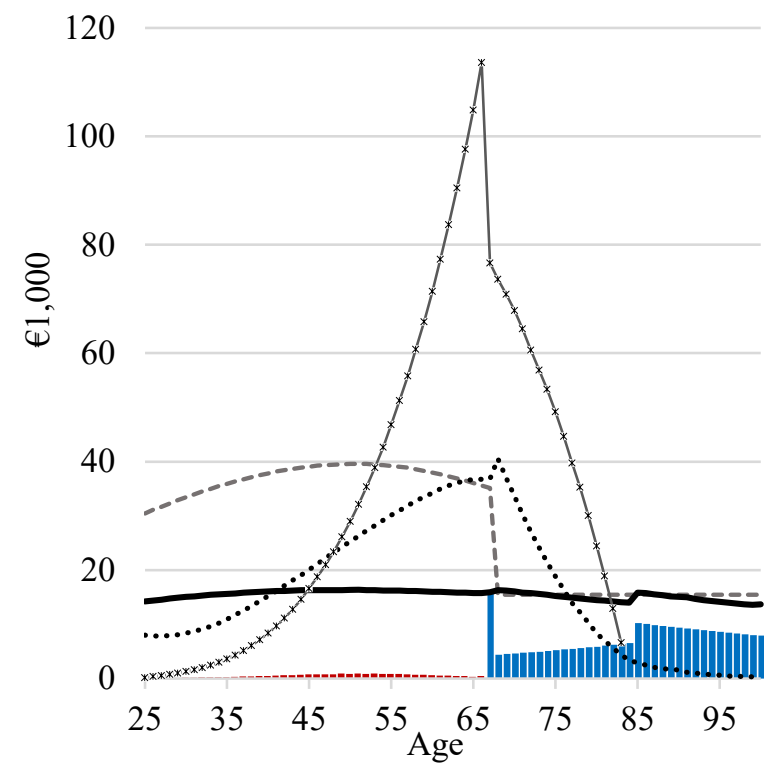

Panel B: Without guarantee

140

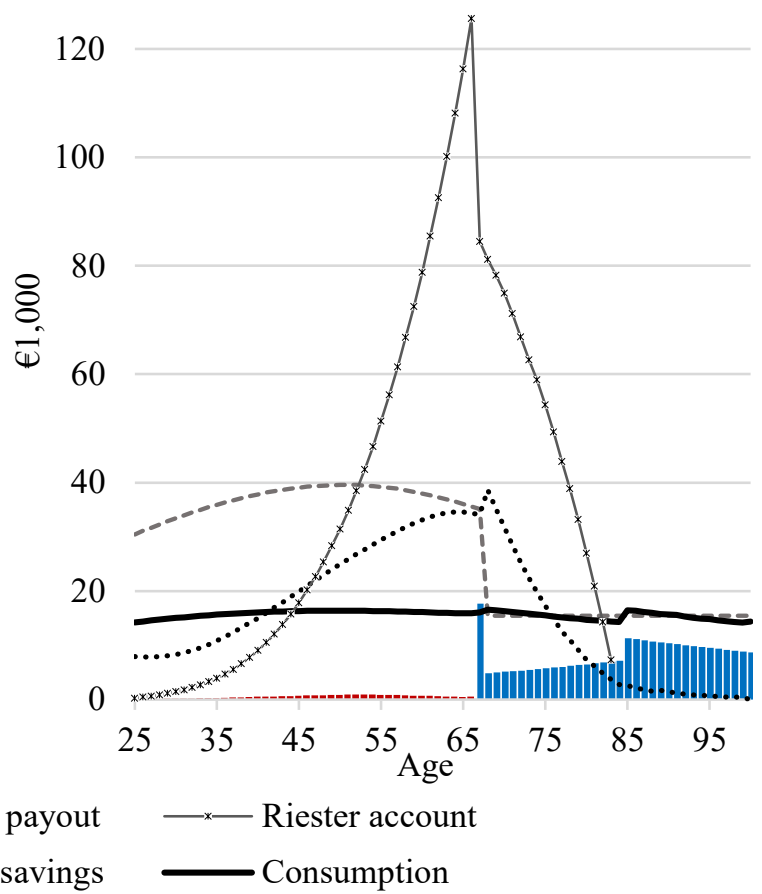

Note: The Figure shows mean values of labor and pension income, non-housing consumption, financial asset holdings (bonds, stocks, and Riester account balances), and retirement plan payouts (in €2015). Panel A refers to the base case, where the nominal risk-free rate is $3 \%$ and inflation is $1.75 \%$. Stock investments earn a risk premium of $6 \%$ and volatility of $21.41 \%$. Preference parameters include a discount factor of $\beta=0.93$ and relative risk aversion of $\gamma=7$. Panel B refers to the otherwise identical case without a money-back guarantee in the IRA. Mean values are calculated based on 100,000 simulated life cycles which rely on optimal policies that were derived for all possible combinations of current income, cash on hand, IRA balances, guarantee amounts, and annuity payouts. Prior to retirement at age 67, the IRA is fully invested in equities, from age 67 to 84 the asset allocation consists of $20 \%$ stocks, and $80 \%$ bonds. From age 85 onward, the plan pays out a lifetime annuity. See Section 3 for details. 
Figure 2: IRA Participation Rates and Plan Contributions as a Percent of Gross Labor Income by Age: Base Case

\section{Panel A: Participation rates}

$100 \%$

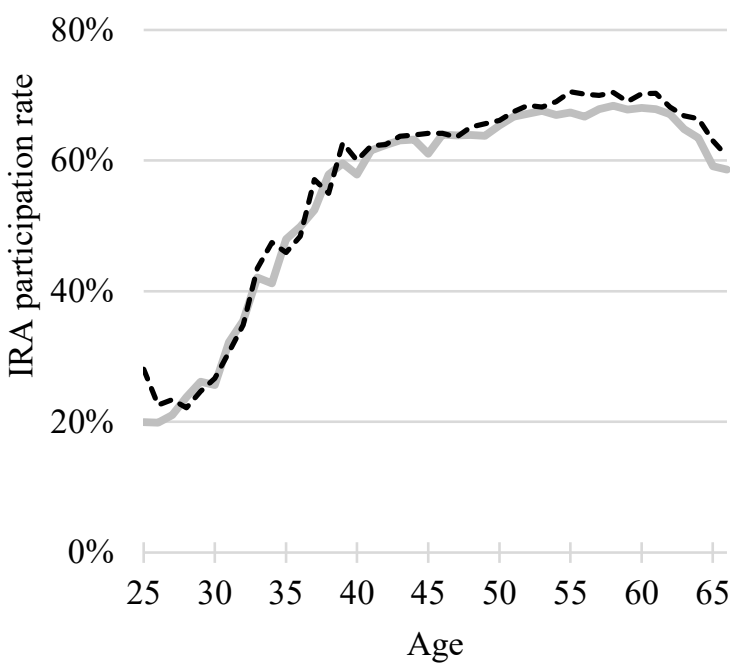

With guarantee ----- Without guarantee
Panel B: Contributions (conditional on participation)

$4.5 \%$

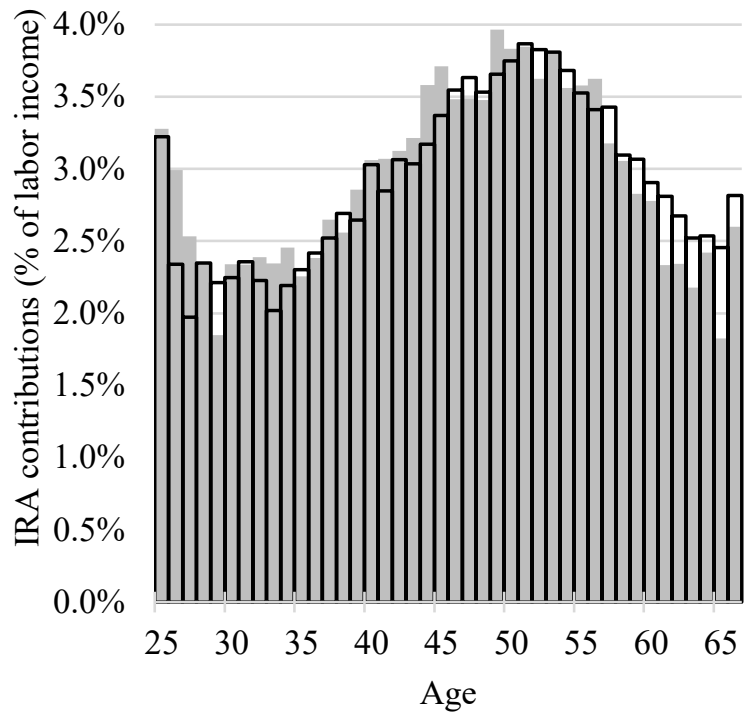

With guarantee $\square$ Without guarantee

Note: Panel A shows the fraction of individuals making contributions to the IRA by age under the two alternative scenarios. For additional notes on base case parameters, see Figure 1. Panel B of the Figure illustrates the pattern of average contributions (including subsidies) to IRAs (conditional on participation) as a percent of gross labor income by age, with and without a money-back guarantee. Results are drawn from 100,000 simulated optimal life cycles. 
Figure 3: Consumption Differences and Percent Better off by Age Without versus With the IRA Guarantee: Base Case
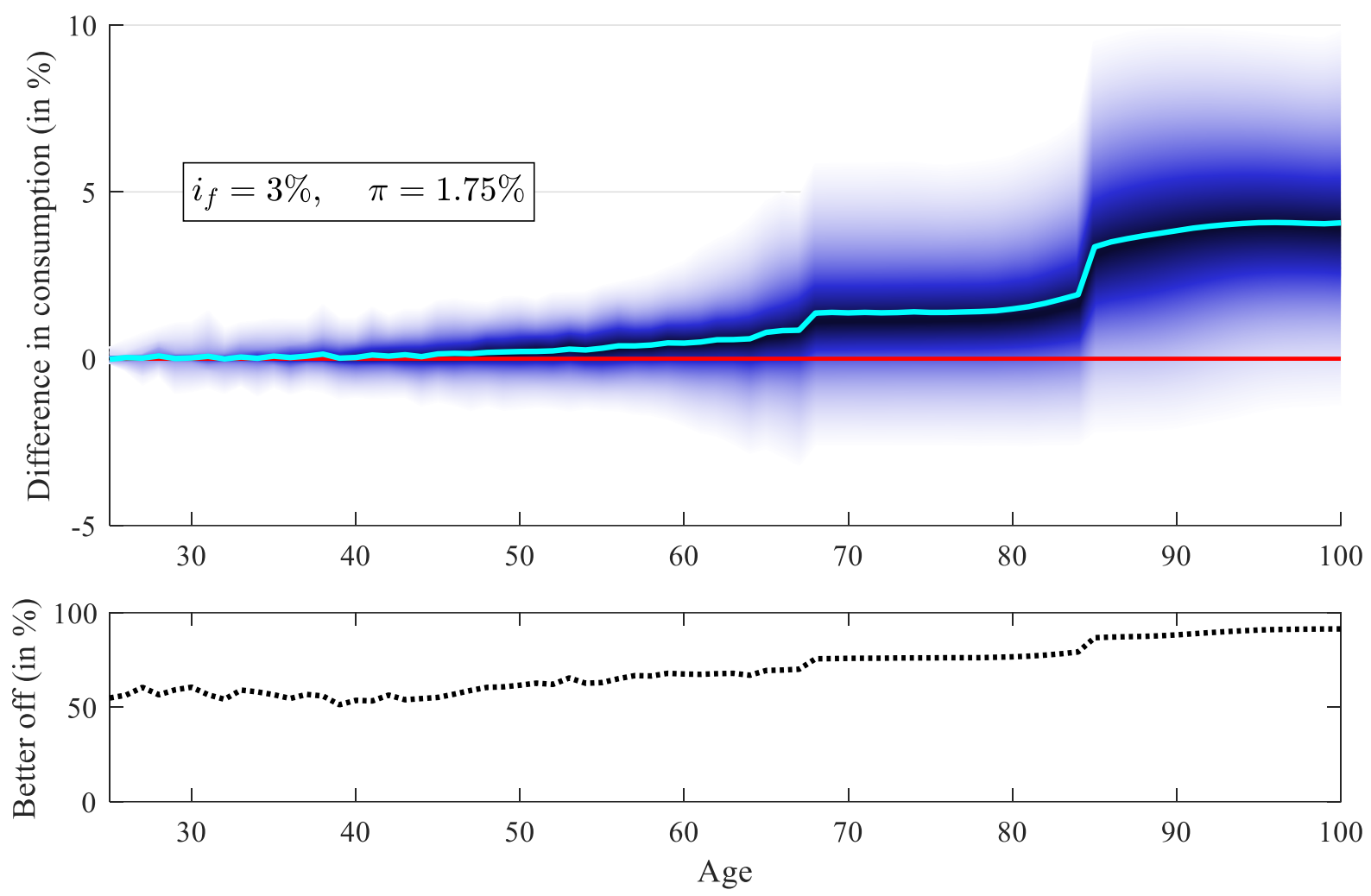

Note: The fan chart at the top of the Figure illustrates path-wise differences in non-housing consumption drawn from 100,000 simulated optimal life cycles for IRAs without versus with a money-back guarantee. The cyan line represents the mean consumption difference, while darker areas indicate a higher probability density (between the 5 and 95\% quantiles). Differences are expressed as a percent of optimal consumption with the money-back guarantee. The bottom panel shows the percentage of individuals with higher optimal consumption without versus with the money-back guarantee. For further notes on base case parameters see Figure 1. 
Figure 4: Heterogeneity of Impacts by Lifetime Income of Abolishing the IRA Guarantee: Contributions and Old-Age Consumption
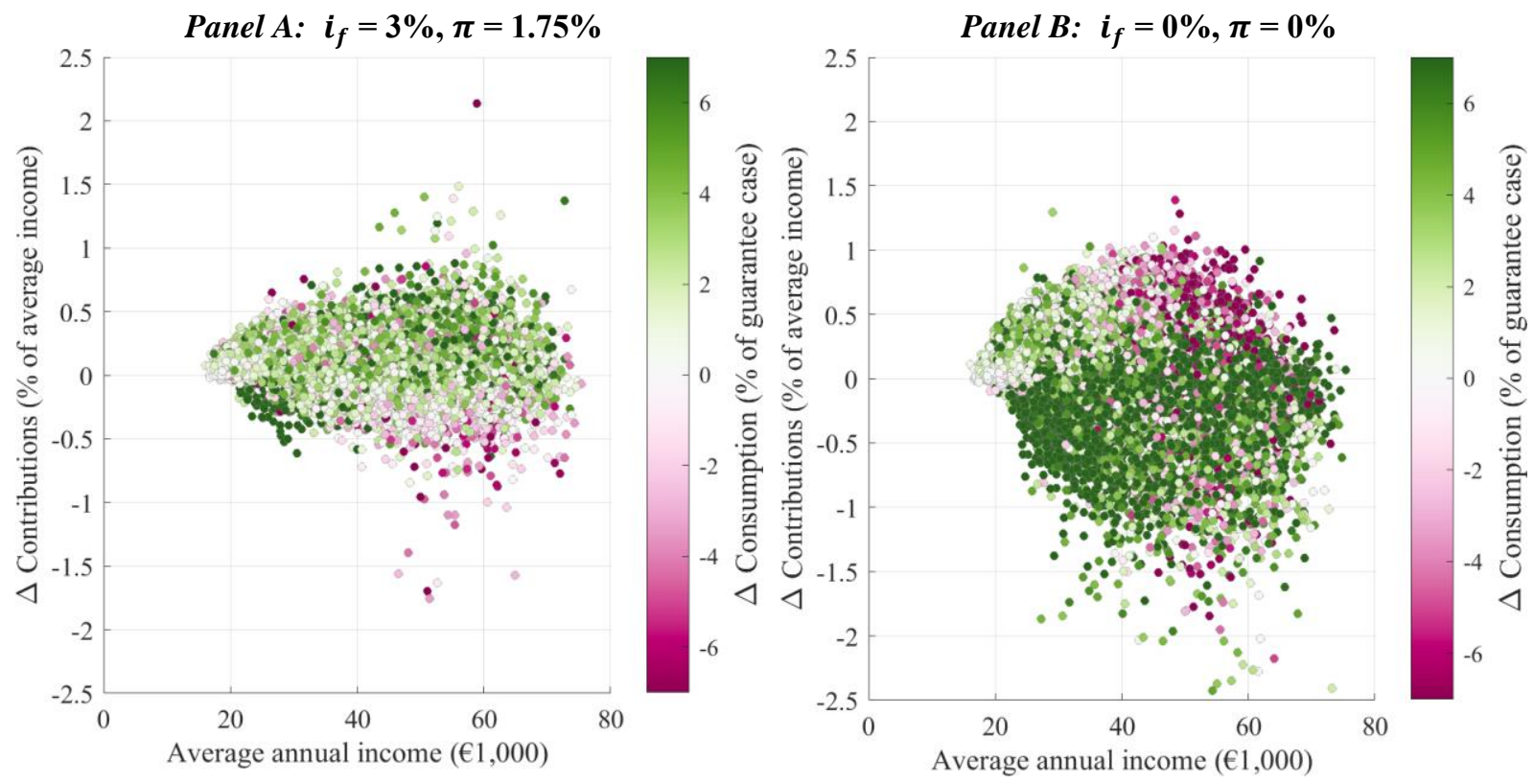

Note: This Figure illustrates the effects of abolishing the money-back guarantee on total contributions (including subsidies; in percent of average labor income), and average non-housing consumption during retirement, by average lifetime earnings for a normal (Panel A) and a low (Panel B) interest rate and inflation scenario. Changes in consumption are in percent of the guarantee case. Consumption increases (decreases) are indicated by green (purple) circles and color intensity is stronger for larger changes (white circles indicate tiny changes). Results are drawn from 100,000 simulated optimal life cycles. Further notes on parameters see Figure 1. 
Figure 5: Consumption and Welfare after an Equity Market Crash in the Low Interest Rate Scenario
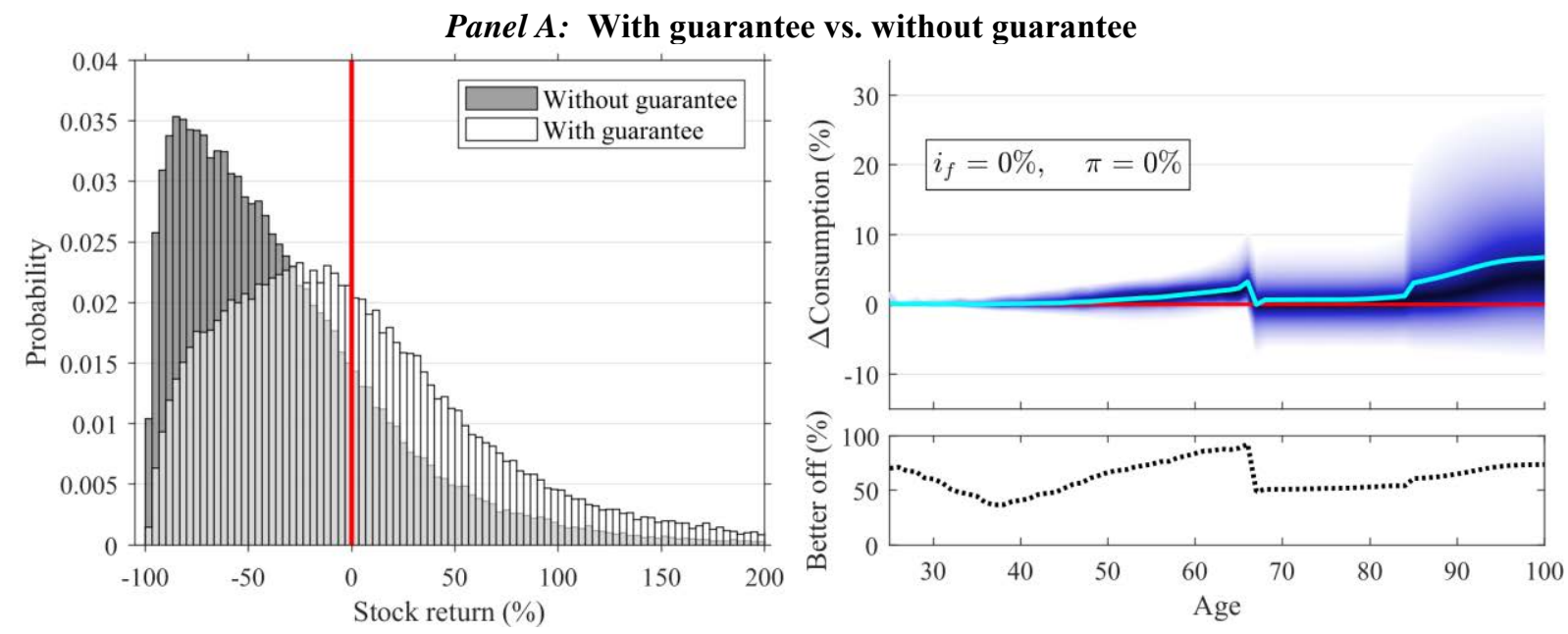

Panel B: With guarantee vs. life cycle fund ' 100 minus age'
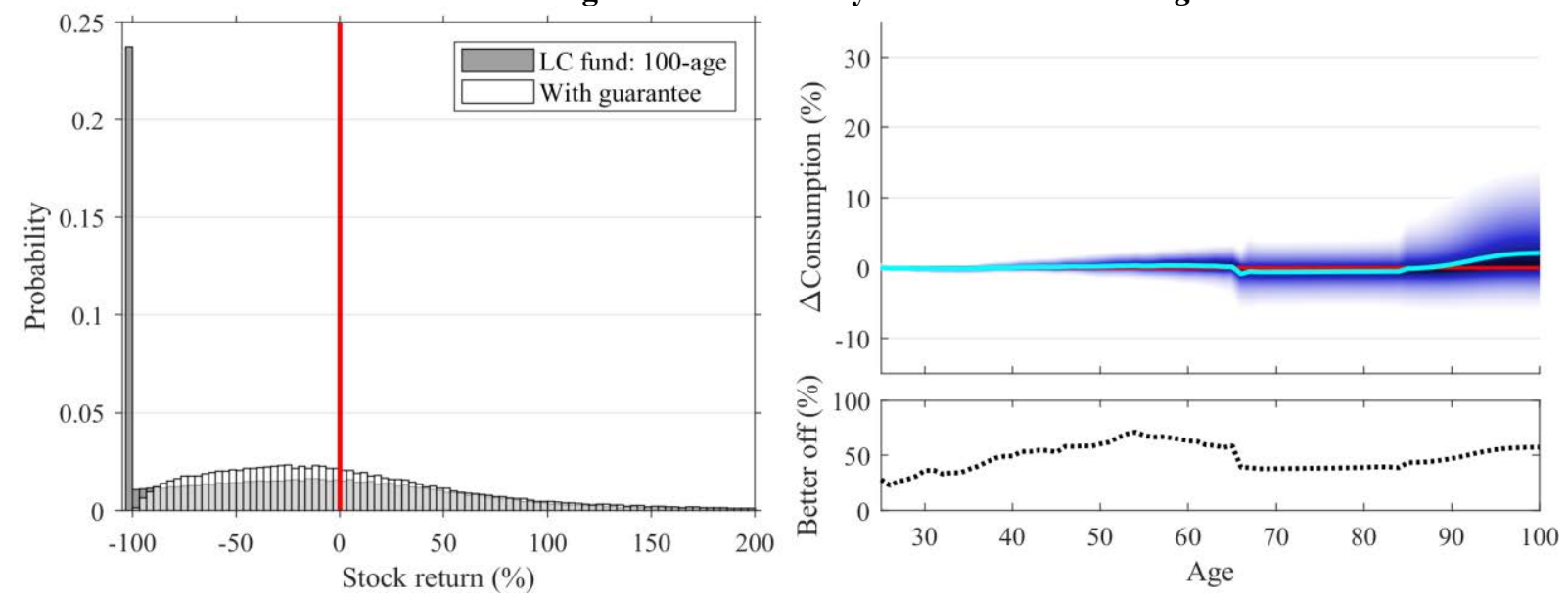

Panel C: With guarantee vs. life cycle fund '100-until-40, -2.5 '
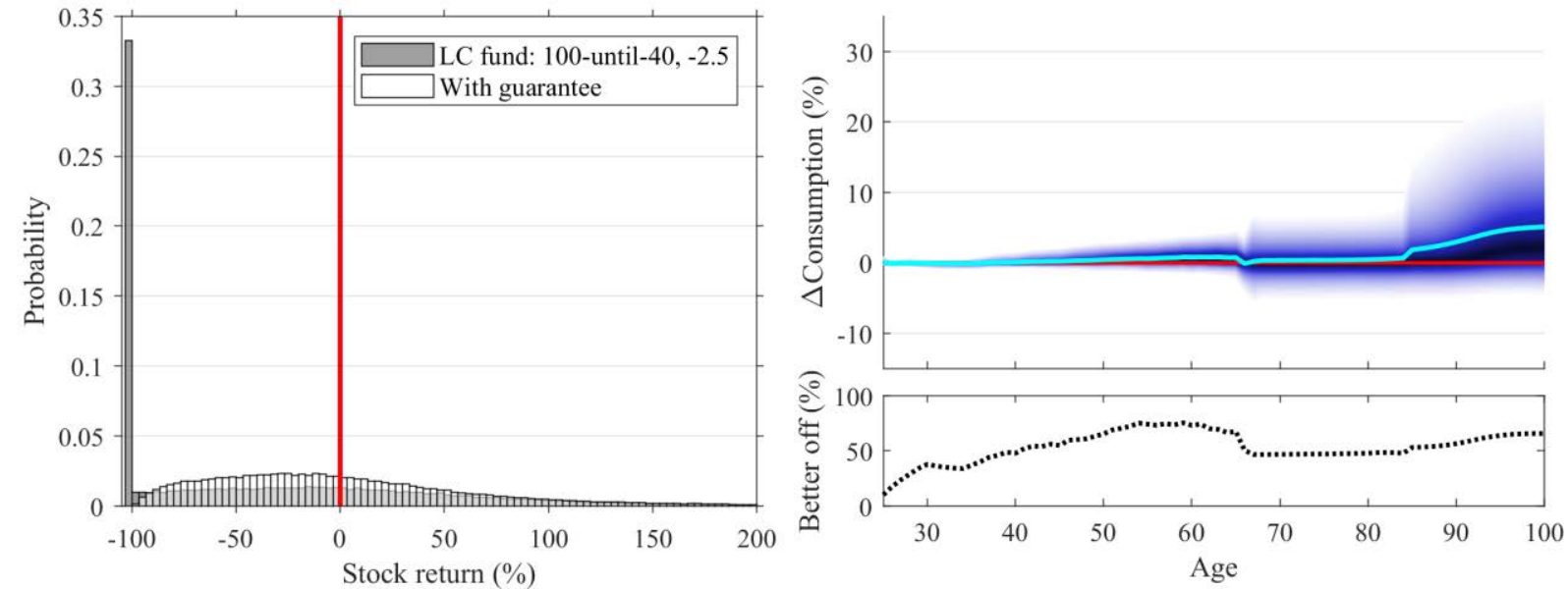

Note: The figure shows the performance of various risk-mitigation techniques in the low interest scenario. We consider schemes with money-back guarantee and alternatives without guarantee (Panel A), and life cycle funds, which govern the equity share according to a ' 100 minus age' rule (Panel B) and a '100-until-40, -2.5 ' rule (Panel C). The histograms illustrate the frequency of the distance to guarantee payoff, which is the last work period's return that would equate the IRA balance at retirement to the guarantee amount. The fan charts show path-wise differences in consumption given that an unanticipated equity market crash of $-35 \%$ happens in the period before retirement for IRAs with guarantees versus IRAs with alternative risk-mitigation techniques. All remaining explanations are analogous to those of Figure 3. 
Table 1: Costs and Benefits of IRA Money-back Guarantees for Participants and Providers (as a \% of total contributions)

\begin{tabular}{|c|c|c|c|c|}
\hline Investment horizon (years) & 42 & 30 & 20 & 10 \\
\hline \multicolumn{5}{|c|}{ Panel A: Guarantee Costs Charged to Participant } \\
\hline $\mathrm{i}_{\mathrm{f}}=3 \%$ & 9.7 & 10.7 & 11.2 & 10.9 \\
\hline $\mathrm{i}_{\mathrm{f}}=0 \%$ & 35.8 & 30.8 & 25.7 & 19.0 \\
\hline \multicolumn{5}{|c|}{ Panel B: Mean Guarantee Payouts to Participant } \\
\hline $\mathrm{i}_{\mathrm{f}}=3 \%$ & 3.1 & 4.3 & 5.8 & 7.6 \\
\hline $\mathrm{i}_{\mathrm{f}}=0 \%$ & 21.9 & 21.0 & 19.5 & 16.9 \\
\hline \multicolumn{5}{|c|}{ Panel C: Mean Profits for Provider (Put Hedge Approach) } \\
\hline $\mathrm{i}_{\mathrm{f}}=3 \%$ & 2.2 & 1.6 & 0.7 & -0.8 \\
\hline $\mathrm{i}_{\mathrm{f}}=0 \%$ & -7.0 & -6.7 & -6.3 & -5.5 \\
\hline
\end{tabular}

Note: Table 1 reports as a \% of total contributions the costs (Panel A), mean payouts to the IRA participant (Panel $\mathrm{B})$, and mean profits of the product provider resulting from using fairly-priced put options to hedge the moneyback guarantee on contributions (Panel C). The example assumes constant annual contributions, and the guarantee is provided at the end of the investment horizon. The product provider buys at-the-money put options maturing at retirement to hedge downside risk for each contribution amount. Option pricing follows Black and Scholes (1973) with an assumed equity volatility of $21.41 \%$ p.a. and interest rates of $3 \%$ and $0 \%$. The simulation relies on 100,000 Monte Carlo paths using the same volatility and an equity risk premium of $6 \%$. 
Table 2: Heterogeneity Analysis for High, Middle, and Low Income Workers: Base Case

\begin{tabular}{|c|c|c|c|c|c|c|}
\hline Lifetime income & Top & & Mide & $0 \%$ & Bottc & $0 \%$ \\
\hline Guarantee & With & Without & With & Without & With & Without \\
\hline Panel A: Consur & 1,000 or 1 & nt of guar & ase) & & & \\
\hline Age 25-39 & 18.34 & $100 \%$ & 15.35 & $100 \%$ & 11.88 & $100 \%$ \\
\hline Age $40-59$ & 23.05 & $101 \%$ & 15.79 & $100 \%$ & 11.26 & $100 \%$ \\
\hline Age 60-79 & 25.17 & $102 \%$ & 14.91 & $101 \%$ & 9.02 & $101 \%$ \\
\hline Age $80-100$ & 23.65 & $103 \%$ & 14.17 & $104 \%$ & 7.29 & $103 \%$ \\
\hline
\end{tabular}

Panel B: Liquid Savings (in $€ 1,000$ or percent of guarantee case)

$\begin{array}{lrrrrrr}\text { Age } 25-39 & 19.83 & 99 \% & 9.40 & 99 \% & 2.88 & 99 \% \\ \text { Age 40-59 } & 77.47 & 99 \% & 16.56 & 97 \% & 3.50 & 97 \% \\ \text { Age 60-79 } & 76.81 & 97 \% & 21.85 & 92 \% & 8.13 & 90 \% \\ \text { Age 80-100 } & 7.17 & 93 \% & 1.67 & 91 \% & 0.68 & 82 \%\end{array}$

Panel C: IRA Balance (in $€ 1,000$ or percent of guarantee case)

$\begin{array}{rrrrrrr}\text { Age } 25-39 & 6.00 & 108 \% & 2.50 & 109 \% & 0.30 & 120 \% \\ \text { Age 40-59 } & 66.57 & 108 \% & 29.31 & 110 \% & 4.09 & 120 \% \\ \text { Age 60-79 } & 136.82 & 109 \% & 65.17 & 111 \% & 12.74 & 122 \% \\ \text { Age 80-84 } & 31.73 & 109 \% & 15.06 & 111 \% & 2.94 & 121 \%\end{array}$

Panel D: IRA Payouts (in $€ 1,000$ or percent of guarantee case)

$\begin{array}{lllllll}\text { Age 67: lump sum } & 31.03 & 108 \% & 15.18 & 112 \% & 4.07 & 124 \% \\ \text { Age 68-84: drawdown } & 10.87 & 109 \% & 5.16 & 111 \% & 1.01 & 121 \% \\ \text { Age 85-100: annuity } & 18.06 & 109 \% & 8.61 & 111 \% & 1.79 & 122 \%\end{array}$

Panel E: Share of Consumption and Housing Costs Financed by IRA Payouts (\%)

$\begin{array}{lllllll}\text { Age 68-84: drawdown } & 29.6 & 31.7 & 19.9 & 21.7 & 4.6 & 5.4 \\ \text { Age 85-100: annuity } & 51.3 & 54.1 & 32.8 & 35.2 & 7.5 & 8.8\end{array}$

Panel F: IRA Shortfall Probability (\%)
Age 67
0.0
3.9
0.0
5.7
0.0
11.5

Note: Panels A-D of Table 2 show mean values (in $€ 1,000)$ of annual non-housing consumption, liquid assets, IRA balances, and payouts, by age ranges, for the top $10 \%$, middle $10 \%$, and bottom $10 \%$ of lifetime income earners. Results for columns labeled 'Without' indicate the percent of the respective guarantee values. Panel E quantifies the share (in \%) of both consumption and housing costs financed by after-tax payouts from the IRA. Panel F reports the share of simulations where the IRA value at retirement falls short of the sum of contributions and subsidies. IRA assets are held entirely in stocks until retirement (protected with the hedges described above), while after retirement only $20 \%$ is allocated to stocks and $80 \%$ to bonds. Subgroups are generated using $1,000,000$ simulation optimal life cycle paths and summing up individual lifetime labor incomes (all in real terms). For further notes on base case parameters see Figure 1 . 
Table 3: Percent of Individuals by Age and Lifetime Income Decile Having Higher Consumption Without versus With the IRA Guarantee: Base Case

\begin{tabular}{|c|c|c|c|c|}
\hline Age & $25-39$ & $40-59$ & $60-79$ & $80-100$ \\
\hline Top $10 \%$ & 59 & 72 & 68 & 81 \\
\hline Middle $10 \%$ & 58 & 61 & 75 & 88 \\
\hline Bottom 10\% & 51 & 46 & 72 & 89 \\
\hline
\end{tabular}

Note: Table 3 reports the percent of individuals having higher non-housing consumption without the money-back guarantee, by age and lifetime income decile. Subgroups are generated using 1,000,000 simulation paths for optimal life cycles, adding up individual lifetime labor incomes (in real terms). The baseline case calibration uses a nominal risk-free rate of $3 \%$ and inflation rate of $1.75 \%$.

Table 4: Percent of Individuals by Age and Lifetime Income Decile Having Positive IRA Contributions, Without versus With the IRA Guarantee: Base Case

\begin{tabular}{|c|c|c|c|c|c|c|}
\hline \multirow{2}{*}{$\begin{array}{l}\text { Age } \\
\text { Guarantee }\end{array}$} & \multicolumn{2}{|c|}{$25-39$} & \multicolumn{2}{|c|}{$40-59$} & \multicolumn{2}{|c|}{$60-66$} \\
\hline & With & Without & With & Without & With & Without \\
\hline Top 10\% & 63 & 64 & 84 & 90 & 68 & 71 \\
\hline Middle $10 \%$ & 38 & 39 & 67 & 68 & 62 & 64 \\
\hline Bottom $10 \%$ & 10 & 11 & 35 & 35 & 67 & 71 \\
\hline
\end{tabular}

Note: Table 4 reports the percent of individuals with positive contribution rates with and without the money-back guarantee, by age and lifetime income decile. Subgroups are generated using 1,000,000 simulation paths, adding up individual lifetime labor incomes (in real terms). For further notes on base case parameters see Figure 1. 
Table 5: Impacts of Different Guarantees: Base Case

\begin{tabular}{|c|c|c|c|c|c|c|}
\hline Guarantee & $\begin{array}{c}\text { With } \\
\text { (nominal) }\end{array}$ & Without & $\begin{array}{l}\text { With } \\
\text { (real) }\end{array}$ & $\begin{array}{c}\text { With } \\
\text { (nominal) }\end{array}$ & Without & $\begin{array}{l}\text { With } \\
\text { (real) }\end{array}$ \\
\hline $\mathrm{i}_{\mathrm{f}}$ & \multicolumn{3}{|c|}{$3 \%$} & \multicolumn{3}{|c|}{$0 \%$} \\
\hline$\pi$ & \multicolumn{3}{|c|}{$1.75 \%$} & \multicolumn{3}{|c|}{$0 \%$} \\
\hline \multicolumn{7}{|c|}{ Panel A: Consumption (in $€ 1,000$ or percent of guarantee case) } \\
\hline Age $25-39$ & 15.22 & $100 \%$ & $100 \%$ & 15.15 & $100 \%$ & \multirow{4}{*}{$\begin{array}{l}\text { Same as } \\
\text { for With } \\
\text { (nominal) }\end{array}$} \\
\hline Age $40-59$ & 16.24 & $100 \%$ & $100 \%$ & 15.86 & $101 \%$ & \\
\hline Age $60-79$ & 15.64 & $101 \%$ & $98 \%$ & 14.28 & $103 \%$ & \\
\hline Age $80-100$ & 14.55 & $104 \%$ & $94 \%$ & 11.17 & $111 \%$ & \\
\hline
\end{tabular}

Panel B: Liquid Savings (in $€ 1,000$ or percent of guarantee case)

$\begin{array}{lrrrrr}\text { Age } 25-39 & 9.92 & 99 \% & 103 \% & 10.77 & 95 \% \\ \text { Age } 40-59 & 24.61 & 98 \% & 105 \% & 31.49 & 89 \% \\ \text { Age 60-79 } & 28.67 & 94 \% & 108 \% & 41.45 & 82 \% \\ \text { Age } 80-100 & 2.25 & 90 \% & 103 \% & 3.74 & 67 \%\end{array}$

Panel C: IRA Balance (in $€ 1,000$ or percent of guarantee case)

$\begin{array}{rrrrrr}\text { Age 25-39 } & 2.66 & 109 \% & 73 \% & 0.77 & 287 \% \\ \text { Age 40-59 } & 31.05 & 109 \% & 81 \% & 11.56 & 204 \% \\ \text { Age 60-79 } & 68.11 & 110 \% & 83 \% & 25.44 & 178 \% \\ \text { Age 80-84 } & 15.74 & 110 \% & 84 \% & 5.12 & 175 \%\end{array}$

Panel D: IRA Payouts (in $€ 1,000$ or percent of guarantee case)

$\begin{array}{lrrrrr}\text { Age 67: lump sum } & 15.92 & 111 \% & 83 \% & 7.92 & 150 \% \\ \text { Age 68-84: drawdown } & 5.40 & 110 \% & 84 \% & 1.91 & 175 \% \\ \text { Age 85-100: annuity } & 9.02 & 111 \% & 84 \% & 3.17 & 170 \%\end{array}$

Panel E: Share of Consumption and Housing Costs Financed by IRA Payouts (\%)

$\begin{array}{lllrrr}\text { Age 68-84: drawdown } & 20.2 & 21.9 & 17.4 & 8.3 & 13.8 \\ \text { Age 85-100: annuity } & 33.9 & 36.3 & 30.0 & 14.9 & 23.2\end{array}$

Panel F: IRA Shortfall Probability (\%)
Age 67
0.0
6.4
0.0
0.0
18.1

Note: Panels A-D of Table 5 show mean values (in $€ 1,000)$ of annual non-housing consumption, liquid assets, IRA balances, and payouts for a real rather than a nominal money-back guarantee (the latter as percent of the guarantee case). Panel E quantifies the share (in \%) of both consumption and housing costs which is financed by after-tax payouts from the IRA. Panel F reports the share of simulations where the IRA value at retirement falls short of the sum of contributions and subsidies. For the first three specifications the nominal risk-free rate and inflation rate are assumed as constant at rates of $i_{f}=3 \%$ and $\pi=1.75 \%$, and the equity risk premium is $6 \%$ (with volatility of $21.41 \%$ ). The latter three specifications refer to a low interest rate and inflation scenario with rates of $i_{f}=0 \%$ and $\pi=0 \%$. Naturally, for zero inflation the results for the real guarantee match those of the nominal guarantee. 
Table 6: Outcomes of Alternative Life Cycle Risk Mitigation Techniques versus IRA Money-Back Guarantee

\begin{tabular}{|c|c|c|c|}
\hline Plan design & $\begin{array}{c}\text { With } \\
\text { guarantee }\end{array}$ & $\begin{array}{l}\text { LC fund } \\
\text { '100-age' }\end{array}$ & $\begin{array}{l}\text { LC fund } \\
\text { '100-until- } \\
40,-2.5 \text { ' }\end{array}$ \\
\hline $\mathrm{i}_{\mathrm{f}}$ & \multicolumn{3}{|c|}{$3 \%$} \\
\hline$\pi$ & \multicolumn{3}{|c|}{$1.75 \%$} \\
\hline
\end{tabular}

\begin{tabular}{ccc}
$\begin{array}{c}\text { With } \\
\text { guarantee }\end{array}$ & $\begin{array}{c}\text { LC fund } \\
\text { '100-age' }\end{array}$ & $\begin{array}{c}\text { LC fund } \\
\text { '100-until- } \\
40,-2.5\end{array}$ \\
\hline & \\
$0 \%$ & \\
\hline
\end{tabular}

Panel A: Consumption (in $€ 1,000$ or percent of guarantee case)

$\begin{array}{lrrrrrr}\text { Age } 25-39 & 15.22 & 100 \% & 100 \% & 15.15 & 100 \% & 100 \% \\ \text { Age 40-59 } & 16.24 & 100 \% & 100 \% & 15.86 & 100 \% & 101 \% \\ \text { Age 60-79 } & 15.64 & 95 \% & 97 \% & 14.28 & 99 \% & 100 \% \\ \text { Age 80-100 } & 14.55 & 85 \% & 92 \% & 11.17 & 98 \% & 101 \%\end{array}$

Panel B: Liquid Savings (in $€ 1,000$ or percent of guarantee case)

$\begin{array}{lrrrrrr}\text { Age } 25-39 & 9.92 & 106 \% & 98 \% & 10.77 & 100 \% & 97 \% \\ \text { Age } 40-59 & 24.61 & 104 \% & 94 \% & 31.49 & 99 \% & 94 \% \\ \text { Age } 60-79 & 28.67 & 109 \% & 96 \% & 41.45 & 95 \% & 90 \% \\ \text { Age } 80-100 & 2.25 & 90 \% & 75 \% & 3.74 & 87 \% & 81 \%\end{array}$

Panel C: IRA Balance (in $€ 1,000$ or percent of guarantee case)

$\begin{array}{rrrrrrr}\text { Age } 25-39 & 2.66 & 77 \% & 117 \% & 0.77 & 199 \% & 279 \% \\ \text { Age 40-59 } & 31.05 & 80 \% & 109 \% & 11.56 & 126 \% & 169 \% \\ \text { Age 60-79 } & 68.11 & 62 \% & 82 \% & 25.44 & 98 \% & 122 \% \\ \text { Age } 80-84 & 15.74 & 60 \% & 79 \% & 5.12 & 93 \% & 114 \%\end{array}$

Panel D: IRA Payouts (in $€ 1,000$ or percent of guarantee case)

$\begin{array}{lrlllll}\text { Age 67: lump sum } & 15.92 & 56 \% & 76 \% & 7.92 & 92 \% & 107 \% \\ \text { Age 68-84: drawdown } & 5.40 & 60 \% & 79 \% & 1.91 & 93 \% & 115 \% \\ \text { Age 85-100: annuity } & 9.02 & 59 \% & 78 \% & 3.17 & 93 \% & 113 \%\end{array}$

Panel E: Share of Consumption and Housing Costs Financed by IRA Payouts (\%)

$\begin{array}{lrrrrrr}\text { Age 68-84: drawdown } & 20.2 & 13.3 & 16.9 & 8.3 & 7.8 & 9.5 \\ \text { Age 85-100: annuity } & 33.9 & 23.4 & 28.9 & 14.9 & 14.1 & 16.7\end{array}$

Panel F: IRA Shortfall Probability (\%)
Age 67
0.0
0.9
1.3
0.0
18.7
17.6

Note: Panels A-D of Table 6 show mean values (in $€ 1,000)$ of annual non-housing consumption, liquid assets, IRA balances, and payouts, by age ranges, for three plan designs and two capital market environments, with the money-back guarantee. Results for columns labeled LC fund '100-age' and LC fund '100-until-40, -2.5 ' indicate the percent of the respective guarantee values. Panel E quantifies the share (in \%) of both consumption and housing costs financed by after-tax payouts from the IRA. Panel F reports the share of simulations where the IRA value at retirement falls short of the sum of contributions and subsidies. The first three (second three) columns use a nominal risk-free rate of $3 \%(0 \%)$ and inflation rate of $1.75 \%(0 \%)$, respectively. For the plan design with the guarantee, IRA contributions (minus put premiums) are invested entirely in stocks until retirement. For the life cycle funds, the fraction of assets invested in risky stocks versus bonds is specified according to a '100-age' rule (or ' 100 -until-40, -2.5 ' rule, respectively) with no money-back guarantee. To maintain consistency, in all plan designs, after retirement only $20 \%$ is allocated to stocks and $80 \%$ to bonds. 
Table 7: Percent of Individuals with Higher Consumption with a Life Cycle Fund versus a Money-Back Guarantee IRA

\begin{tabular}{|c|c|c|c|c|}
\hline Age & $25-39$ & $40-59$ & $60-79$ & $80-100$ \\
\hline \multicolumn{5}{|c|}{ Panel A: 'Normal' Capital Markets $\left(i_{f}=3 \%, \pi=1.75 \%\right)$} \\
\hline '100-age' rule & 47 & 42 & 33 & 32 \\
\hline '100-until-40, -2.5 ' rule & 40 & 48 & 43 & 46 \\
\hline \multicolumn{5}{|c|}{ Panel B: 'Low Return' Capital Markets $\left(i_{f}=0 \%, \pi=0 \%\right)$} \\
\hline '100-age' rule & 35 & 61 & 43 & 44 \\
\hline '100-until-40, -2.5' rule & 34 & 64 & 54 & 55 \\
\hline
\end{tabular}

Note: Table 7 shows the fraction (in \%) of individuals having higher non-housing consumption under two life cycle risk mitigation strategies, relative to a money-back guarantee and $100 \%$ equity allocation throughout the accumulation phase. To determine the percentage equity allocation, the first life cycle fund applies a relatively conservative ' 100 -age' rule, and the second one is fully invested in equities until age 40 and then reduces its equity allocation by 2.5 percentage points per year (termed ' 100 -until-40, -2.5 ' rule). To maintain consistency, in all plan designs, after retirement only $20 \%$ are allocated to stocks and $80 \%$ to bonds. Panel A considers the 'normal' capital market scenario (nominal risk-free rate of 3\% and inflation rate of $1.75 \%$ ) and Panel $\mathrm{B}$ addresses the low return environment (nominal risk-free rate and inflation rate of $0 \%$ ). 


\section{References}

Abdellaoui, M., H. Bleichrodt, and C. Paraschiv (2007). "Loss Aversion under Prospect Theory: A Parameter-Free Measurement.” Management Science 53(10): 1659-1674.

Allianz Global Investors (nd). "Pension System in Japan." Pension Funds Online. Accessed 11Feb-2021. https://www.pensionfundsonline.co.uk/content/country-profiles/japan/103

Berardi, A., C. Tebaldi, and F. Trojani (2018). "Consumer Protection and the Design of the Default Option of a Pan-European Pension Product." Working paper. https://ssrn.com/abstract $=3142243$

Black, F. and M. Scholes (1973). "The Pricing of Options and Corporate Liabilities.” Journal of Political Economy 81(3): 637-654.

Bonin, H. (2009). "15 Years of Pension Reform in Germany: Old Successes and New Threats." Geneva Papers on Risk and Insurance 34(4): 548-560.

Börsch-Supan, A., T. Bucher-Koenen, M. Coppola, and B. Lamla (2015). "Savings in Times of Demographic Change: Lessons from the German Experience." Journal of Economic Surveys 29(4): 807-829.

Börsch-Supan, A., M. Coppola, and A. Reil-Held (2012). "Riester Pensions in Germany: Design, Dynamics, Targeting Success, and Crowding-In.” In Matching Contributions for Pensions: A Review of International Experience, Eds. R. P. Hinz, R. Holzmann, D. Tuesta, and N. Takayama. World Bank: 81-102.

Börsch-Supan, A., A. Reil-Held, and D. Schunk (2008). "Saving Incentives, Old-Age Provision and Displacement Effects: Evidence from the Recent German Pension Reform." Journal of Pension Economics and Finance 7(3): 295-319.

Bundesministerium der Finanzen (BMF, 2019). "Statistik zur Riester-Förderung." Accessed 15-Dec-2020. https://www.bundesfinanzministerium.de/Content/DE/Standardartikel/ Themen/Steuern/Steuerliche_Themengebiete/Altersvorsorge/2019-11-15-StatistischeAuswertungen-Riester-Foerderung-bis-2018.html

Bundesministerium für Arbeit und Soziales (BMAS, 2017). "Entwicklung der RiesterVerträge.” Accessed 21-Jun-2017. http://www.bmas.de/SharedDocs/Downloads/DE/ Thema-Rente/riesterrente-I-2017.pdf

Calvet, L. E., C. Célérier, P. Sodini, and B. Vallée (2020). “Can Security Design Foster Household Risk-Taking?" Working Paper.

Carroll, C. D. and A. A. Samwick (1997). "The Nature of Precautionary Wealth." Journal of Monetary Economics 40(1): 41-71.

Célérier, C. and B. Vallée (2017). "Catering to Investors Through Security Design: Headline Rate and Complexity.” Quarterly Journal of Economics 132(3): 1469-1508.

Chai, J., W. Horneff, R. Maurer, and O. S. Mitchell (2011). "Optimal Portfolio Choice over the Life Cycle with Flexible Work, Endogenous Retirement, and Lifetime Payouts." Review of Finance 15(4): 875-907.

Cocco, J. F. and F. J. Gomes (2012). "Longevity Risk, Retirement Savings, and Financial Innovation." Journal of Financial Economics 103(3): 507-529.

Cocco, J. F., F. J. Gomes, and P. J. Maenhout (2005). "Consumption and Portfolio Choice over the Life Cycle.” Review of Financial Studies 18(2): 491-533. 
Deutsche Bundesbank (2016). "Monatsbericht März 2016." Accessed 03-Oct-2017. https://www.bundesbank.de/resource/blob/664820/12eb34cfdb12cf3098c4ab2fca1519 c0/mL/2016-03-monatsbericht-data.pdf

Dolls, M., P. Doerrenberg, A. Peichl, and H. Stichnoth (2018). "Do Retirement Savings Increase in Response to Information about Retirement and Expected Pensions?" Journal of Public Economics 158: 168-179.

Ernst \& Young (2017). "Study on the Feasibility of a European Personal Pension Framework." https://ec.europa.eu/info/sites/info/files/170629-personal-pensions-study_en.pdf.

European Central Bank (2018). "The Definition of Price Stability." Accessed 05-Oct-2018. https://www.ecb.europa.eu/mopo/strategy/pricestab/html/index.en.html

European Commission (2017). "Proposal for a Regulation of the European Parliament and of the Council on a Pan-European Personal Pension Product (PEPP)." Accessed 08-Sep2017. https://eur-lex.europa.eu/legal-content/EN/TXT/HTML/?uri=CELEX:52017PC0 $343 \&$ from $=\mathrm{EN}$

European Parliament (2019). "Regulation (EU) 2019/1238 of the European Parliament and Council of 20 June 2019 on a pan-European Personal Pension Product (PEPP)." Accessed 28-Apr-2020. https://eur-lex.europa.eu/legalcontent/EN/TXT/PDF/?uri=CELEX:32019R1238\&from=EN

Fagereng, A., C. Gottlieb, and L. Guiso (2017). "Asset Market Participation and Portfolio Choice over the Life-Cycle." Journal of Finance 72(2): 705-750.

Fehr, H. and C. Habermann (2008). "Risk Sharing and Efficiency Implications of Progressive Pension Arrangements." Scandinavian Journal of Economics 110(2): 419-443.

Feldstein, M. (2009). "Reducing the Risk of Investment-Based Social Security Reform." In Social Security Policy in a Changing Environment, Eds. J. R. Brown, J. B. Liebman, and D. A. Wise. University of Chicago Press: 201-218.

Feldstein, M. and A. A. Samwick (2002). "Potential Paths of Social Security Reform." Tax Policy and the Economy 16: 181-224.

Fischer, K. P. (1999). "Pricing Pension Fund Guarantees: A Discrete Martingale Approach." Canadian Journal of Administrative Sciences 16(3): 256-266.

Gomes, F. J. (2020). "Portfolio Choice Over the Life Cycle: A Survey." Annual Review of Financial Economics 12: 277-304.

Gomes, F. J., M. Haliassos, and T. Ramadorai (2020a). "Household Finance." Journal of Economic Literature (forthcoming).

Gomes, F. J. and A. Michaelides (2005). "Optimal Life-Cycle Asset Allocation: Understanding the Empirical Evidence.” Journal of Finance 60(2): 869-904.

Gomes, F. J., A. Michaelides, and V. Polkovnichenko (2009). "Optimal Savings with Taxable and Tax-Deferred Accounts." Review of Economic Dynamics 12(4): 718-735.

Gomes, F. J., A. Michaelides, and Y. Zhang (2020b). "Tactical Target Date Funds." Management Science (forthcoming).

Haliassos, M. and C. C. Bertaut (1995). "Why do so Few Hold Stocks?" Economic Journal 105(432): 1110-1129.

Horneff, V., R. Maurer, and O. S. Mitchell (2018). "How Persistent Low Expected Returns Alter Optimal Life Cycle Saving, Investment, and Retirement Behavior." In How 
Persistent Low Returns Will Shape Saving and Retirement, Eds. R. Clark, R. Maurer, and O. S. Mitchell. Oxford University Press: 119-131.

Horneff, V., R. Maurer, O. S. Mitchell, and R. Rogalla (2015). “Optimal Life Cycle Portfolio Choice with Variable Annuities Offering Liquidity and Investment Downside Protection." Insurance: Mathematics and Economics 63: 91-107.

Huang, H., M. A. Milevsky, and V. R. Young (2016). "Optimal Purchasing of Deferred Income Annuities When Payout Yields are Mean-Reverting." Review of Finance 21(1): 327361.

Hubener, A., R. Maurer, and O. S. Mitchell (2016). "How Family Status and Social Security Claiming Options Shape Optimal Life Cycle Portfolios." Review of Financial Studies 29(4): 937-978.

Investment Company Institute (ICI, 2018). "Millions of Workers Continue to Save for Retirement Through 401(k) Plans." Accessed 17-Dec-2018. https://www.ici.org/ 401k/news/18_news_401kday

Investment Company Institute (ICI, 2021). "Frequently Asked Questions About 401(k) Plans: The Basics." Accessed 08-Feb-2021. https://www.ici.org/policy/retirement/plan/ 401k/faqs_401k_basic

Jordà, Ò, K. Knoll, D. Kuvshinov, M. Schularick, and A. M. Taylor (2019). "The Rate of Return on Everything, 1870-2015.” Quarterly Journal of Economics 134(3): 1225-1298.

Kaschützke, B. and R. Maurer (2011). "The Private Life Annuity Market in Germany: Products and Money's Worth Ratios." In Securing Lifelong Retirement Income, Eds. O. S. Mitchell, J. Piggott, and N. Takayama. Oxford University Press: 131-158.

Koijen, R. S., T. E. Nijman, and B. J. Werker (2011). “Optimal Annuity Risk Management." Review of Finance 15(4): 799-833.

Lachance, M.-E. and O. S. Mitchell (2003). "Guaranteeing Individual Accounts." American Economic Review P\&P 93(2): 257-260.

Love, D. A. (2010). "The Effects of Marital Status and Children on Savings and Portfolio Choice." Review of Financial Studies 23(1): 385-432.

Lusardi, A. and O. S. Mitchell (2014). "The Economic Importance of Financial Literacy: Theory and Evidence." Journal of Economic Literature 52(1): 5-44.

Malkiel, B. G. (1996). A Random Walk Down Wall Street: Including a Life-Cycle Guide to Personal Investing. W. W. Norton \& Co Inc.

Maurer, R. and C. Schlag (2003). "Money-Back Guarantees in Individual Pension Accounts: Evidence from the German Pension Reform." In The Pension Challenge: Risk Transfers and Retirement Income Security, Eds. O. S. Mitchell and K. Smetters. Oxford University Press: 187-213.

Mercer (2020). Mercer CFA Institute Global Pension Index. https://www.mercer.com.au/content/dam/mercer/attachments/private/asia-pacific/austr alia/campaigns/mcgpi-2020/MCGPI-2020-full-report-1.pdf

Pennacchi, G. G. (1999). “The Value of Guarantees on Pension Fund Returns.” Journal of Risk and Insurance 66(2): 219-237.

Poterba, J. M., J. Rauh, S. Venti, and D. A. Wise (2006). "Lifecycle Asset Allocation Strategies and the Distribution of 401(k) Retirement Wealth." NBER Working Paper 11974. 
Schmidt, U. and S. Traub (2002). “An Experimental Test of Loss Aversion.” Journal of Risk and Uncertainty 25(3): 233-249.

Union Investment (2018). "Studie: Anlegerbarometer - drittes Quartal 2018." Accessed 11-Oct2018. https://unternehmen.union-investment.de/startseite-unternehmen/presseservice/ $\% 20$ pressemitteilungen/alle-pressemitteilungen/2018/Studie--Anlegerbarometer---dritt es-Quartal-2018.html

van Bilsen, S., I. A. Boelaars, and A. L. Bovenberg (2020). "The Duration Puzzle in Life-Cycle Investment." Review of Finance 24(6): 1271-1311.

Van Hulle, K. (2019). Solvency Requirements for EU Insurers. Cambridge, UK: Intersentia Ltd.

Vanguard (2017). “How America Saves 2017.” https://pressroom.vanguard.com/nonindexed/ How-America-Saves-2017.pdf 


\section{Online Appendix A: Income Taxation and Social Security Contributions}

Our model embeds the German social security and tax regulations as realistically as possible, though below, we show that these institutional details can be generalized to other nations (see Online Appendix F). The state-organized social insurance system includes contributions to pension, unemployment, health, and nursing care insurance. During the worklife, employees and employers each contribute $9.35 \%$ of gross labor income to the statutory pension system and $1.5 \%$ to unemployment insurance (to an assessment ceiling of $€ 71,400$ p.a.). Health insurance costs $7.3 \%$ of labor income and nursing care insurance amounts to $1.175 \%$ for employees (to an assessment ceiling of $€ 48,600$ p.a.). Retirees do not pay pension and unemployment insurance contributions, but they pay $7.3 \%$ from pension income for health and $2.35 \%$ for nursing care insurance.

Federal income taxes are charged based on taxable income, which is gross income less (in part) contributions to the state-organized social insurance system, contributions and subsidies paid into tax-qualified IRAs, and several tax-exempt amounts. In 2015, 80\% of both the employee's and employer's contribution to the statutory pension system could be deducted. This tax deductible contribution is increasing in $2 \%$ increments, such that in 2025 , the full amount can be deducted. In addition, an individual's payments to nursing care insurance and $96 \%$ of the contribution to health insurance are tax deductible. The latter two may be increased by unemployment insurance contributions as long as the sum of the three is below $€ 1,900$. Furthermore, taxable income is reduced by income-related standard deductions of $€ 1,000$ for employees and $€ 102$ for retirees. In the context of our model, contributions and subsidies paid to Riester IRAs are tax deductible up to an annual limit of $€ 2,100$.

The progressive German income tax system grants tax-exemption on the first $€ 8,354$ of taxable income. Between $€ 8,254$ and $€ 52,881$, marginal tax rates increase from $14 \%$ up to $42 \%$ of taxable income. For income above $€ 250,730$ the marginal tax rate is $45 \%$. Taxes determined by these regulations are additionally increased by a solidarity supplement tax of $5.5 \%$. The following figure illustrates the share of total deductions as percentage of gross income $\left(c_{t}^{S S T}\right)$, i.e. social security and tax payments, for both employees and retirees.

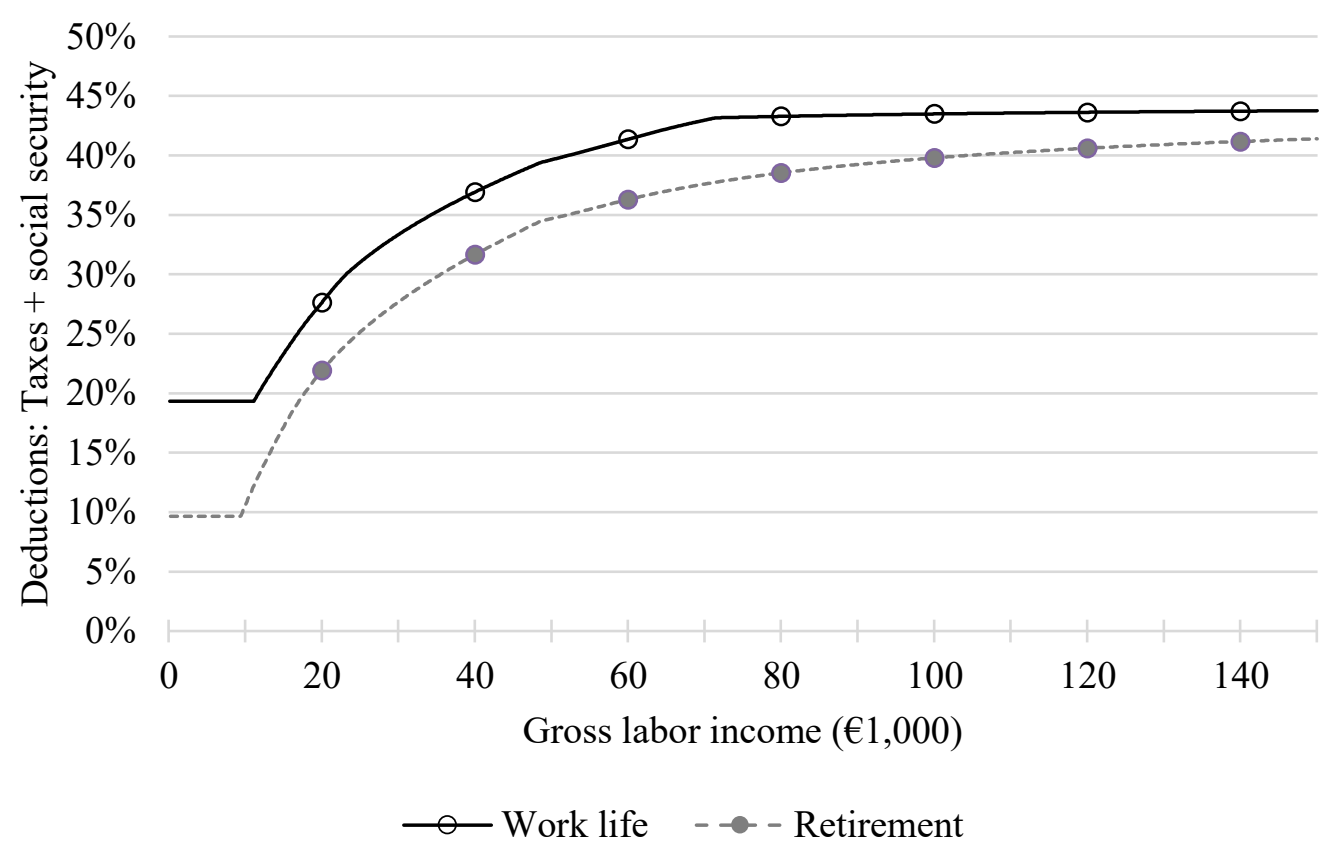

Note: This Figure represents the share of deductions (in \%) from gross labor income resulting from income taxes and contributions to the German social insurance system. The Figure assumes a worker (retiree) with no children and no contributions to (income from) tax-qualified IRAs. 


\section{Online Appendix B: Rental Costs and Number of Children}

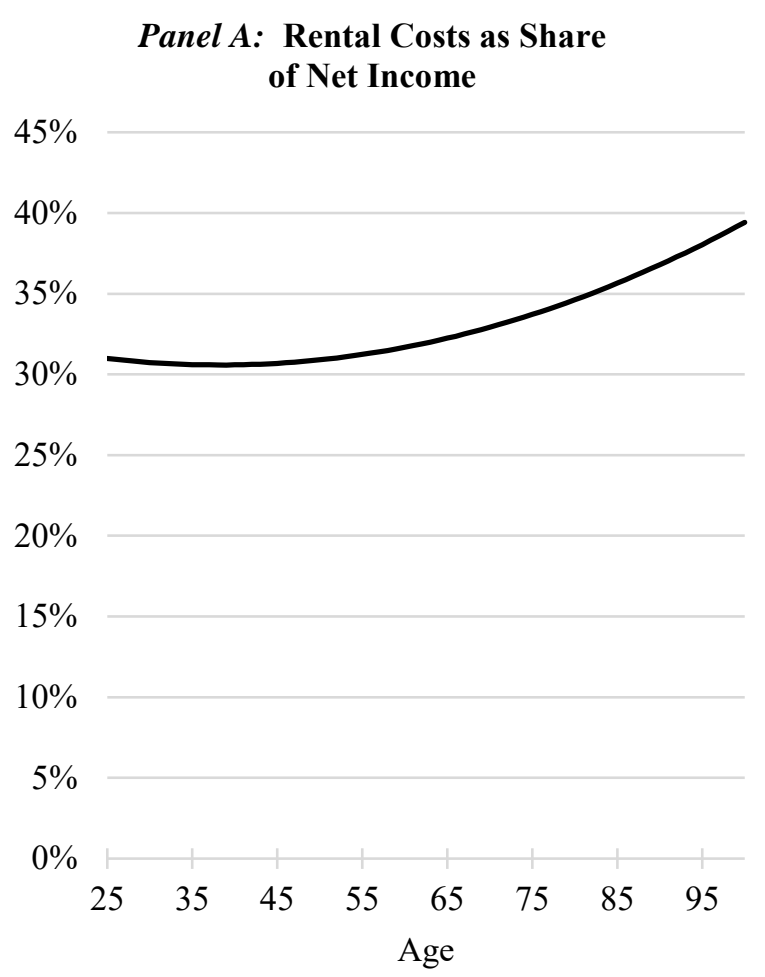

\section{Panel B: Number of Children Living with the Parents}

2.0

1.8

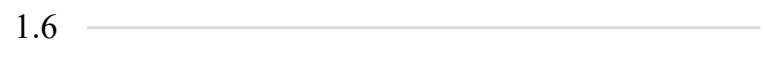

\section{4}

1.2

1.0

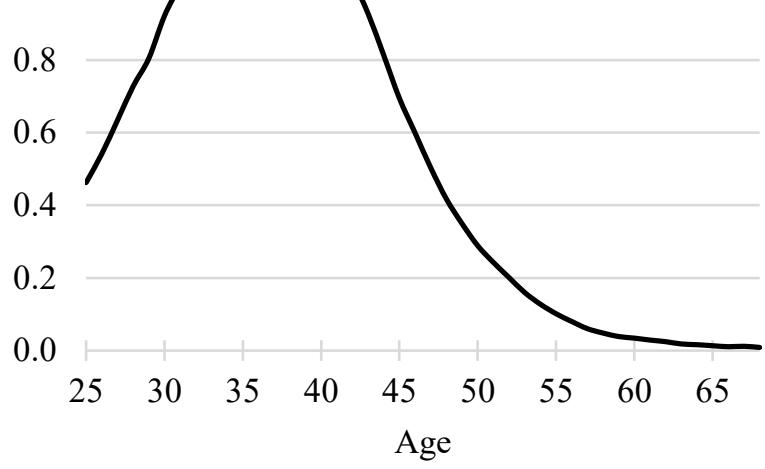

Note: Panel A of this Figure illustrates tenants' rental costs as a fraction of net income $\left(h_{t}\right)$. Raw data are from all waves of SOEP from 1990 to 2015. The definition of housing costs for tenants is broad; besides rental payments we include costs for hot and cold water, heating, garbage disposal, and cleaning services. Housing costs in SOEP are provided solely at the household level, so costs are divided by the aggregate of head's and - if present spouse's net income. The population refers to all households in the panel, irrespective of the potential presence of spouses. The subsamples of females and males do indicate singles' housing costs, but in the model we use population values to avoid the need to make assumptions about relationship status. Panel B illustrates the average number of children living in a household with parents over the life cycle. Raw data were taken from all waves of the Socio-Economic Panel (SOEP) from 1984-2015. 


\section{Online Appendix C: Labor Income Process}

Estimation of the discretized Markovian income process relies on non-zero labor income observations of employed persons aged 25-67 from all waves of SOEP until year 2015. All income figures are converted to year 2015 prices (measured in $€ 1,000$ ) and in all specifications and for every age we drop the top and bottom $1 \%$ of observations to diminish effects of outliers. Next, each remaining observation is assigned to one of $n_{s}$ equally-sized income levels. The lowest (highest) $1 / n_{s}$ of observations are assigned to income level 1 (level $n_{s}$ ), etc. ${ }^{40}$ To estimate deterministic annual income, we conduct pooled OLS regressions for each income level $s$, where the natural logarithm of labor income, $\ln Y_{t, s}$, is regressed on first- and secondorder polynomials in age and year fixed effects. Estimated coefficients are then used to determine predicted age-dependent log income figures, converted to level values and interpreted to (roughly) indicate the level's middle income.

The second component of the labor income process is the variation of observed log income, $\ln Y_{t, s}$, around the regression-based predicted values, $\ln \hat{Y}_{t, s}$. Using the standard deviation of the difference, $\sigma_{u, s}$, as a measure of dispersion, a purely transitory shock is added to the level's deterministic trend. The natural logarithm of the shock is assumed to be normally distributed with $\ln U_{t, s} \sim N\left(-0.5 \sigma_{u, s}^{2}, \sigma_{u, s}^{2}\right)$ and is intended to reflect additional variation in income beyond transitions between income states.

Finally we estimate a Markov transition matrix, which quantifies the probabilities of migrating from current income state $s_{t}$ to all other income states in the next period. To derive migration probabilities, we only consider cases where consecutive observations from one age to the next are available and no change in the highest level of education has occurred. Both the transitory shock component within a level and transition probabilities are assumed to be ageinvariant.

Panel A of Table C.1 shows state-dependent coefficients of the labor earnings regression (all being significant at the $1 \%$ confidence level). Panel B reports the standard deviations $\sigma_{u, s}$ between observed (log) income $Y_{t, s}$ from predicted (log) income $\hat{Y}_{t, s}$ for all levels. The variation is U-shaped in income level, meaning that heterogeneity in labor earnings is higher at more extreme income levels. In addition, the top and bottom level variation is more than twice as high as of the adjacent levels. Panel C quantifies the transition probabilities $q_{s_{t}, s_{t+1}}$ from current income level $s_{t}$ to level $s_{t+1}$ in the next period. Shading in the Table is darker the higher the probability. The likelihood of remaining in the same income level is especially high for top and bottom income deciles, but also for middle income receivers remaining in the same level is the most likely event.

Table C.2 compares the empirical moments of the SOEP data, and of simulated labor income from applying the Markovian and Carroll and Samwick (1997) methods. Despite simplifications with respect to age-independence of transitory shock components and migration probabilities, the empirical moments over age ranges of 10 years are sufficiently close to infer that the Markovian method adequately simulates labor income.

\footnotetext{
${ }^{40}$ Increasing the number of income levels $n_{s}$, is expected to improve the fit between raw data and simulated income data, but also increases model runtime. Overall, we find that for the total population and subsamples of females and males $n_{s}=10$ achieves a satisfactory fit of the distribution parameters of the SOEP data (see Table C.2).
} 
Table C.1: Gross Labor Income Parameters Estimated by Deciles using SOEP

Panel A: Regression Coefficients from Estimated Models of Log Labor Income by Income Decile

\begin{tabular}{lcccccccccc}
\hline Income decile $\mathrm{s}_{\mathrm{t}}$ & 1 & 2 & 3 & 4 & 5 & 6 & 7 & 8 & 9 & 10 \\
\hline Constant & 2.479 & 2.739 & 2.811 & 2.825 & 2.861 & 2.851 & 2.884 & 2.860 & 2.786 & 2.500 \\
& $(63.25)$ & $(134.75)$ & $(123.44)$ & $(220.05)$ & $(277.13)$ & $(267.68)$ & $(247.69)$ & $(205.92)$ & $(148.21)$ & $(72.24)$ \\
Age / 100 & 1.093 & 1.356 & 1.916 & 2.454 & 2.737 & 3.233 & 3.493 & 4.090 & 5.121 & 7.782 \\
& $(5.57)$ & $(13.12)$ & $(15.72)$ & $(37.62)$ & $(53.19)$ & $(61.58)$ & $(60.53)$ & $(61.29)$ & $(54.70)$ & $(45.78)$ \\
Age $^{2} /(100)^{2}$ & -1.439 & -1.613 & -2.150 & -2.655 & -2.878 & -3.372 & -3.522 & -4.051 & -5.050 & -7.794 \\
& $(-6.08)$ & $(-12.68)$ & $(-14.13)$ & $(-33.08)$ & $(-45.93)$ & $(-53.02)$ & $(-50.36)$ & $(-50.16)$ & $(-44.06)$ & $(-37.90)$ \\
Number of obs. & & & & & & & & & & \\
F & 17,502 & 17,463 & 17,459 & 17,391 & 17,382 & 17,449 & 17,449 & 17,399 & 17,515 & 17,407 \\
Prob > F & 4.01 & 8.72 & 43.89 & 168.32 & 308.38 & 395.63 & 475.42 & 502.74 & 537.94 & 262.73 \\
Adj. R-squared & 0.0 & 0.0 & 0.0 & 0.0 & 0.0 & 0.0 & 0.0 & 0.0 & 0.0 & 0.0 \\
& 0.018 & 0.046 & 0.151 & 0.374 & 0.543 & 0.620 & 0.659 & 0.669 & 0.661 & 0.452
\end{tabular}

Panel B: Standard Deviation: Difference of Actual from Predicted Log Labor Income

\begin{tabular}{lcccccccccc}
\hline Income decile $\mathrm{s}_{\mathrm{t}}$ & 1 & 2 & 3 & 4 & 5 & 6 & 7 & 8 & 9 & 10 \\
\hline$\sigma_{\mathrm{u}, \mathrm{s}}$ & 0.166 & 0.073 & 0.055 & 0.043 & 0.037 & 0.038 & 0.043 & 0.053 & 0.069 & 0.158
\end{tabular}

Panel C: Transition Probabilities between Labor Income Deciles $s_{t}, s_{t+1}(\%)$

\begin{tabular}{|c|c|c|c|c|c|c|c|c|c|c|}
\multicolumn{1}{c|}{} & 1 & 2 & 3 & 4 & 5 & 6 & 7 & 8 & 9 & 10 \\
\hline 1 & 61.90 & 25.09 & 5.94 & 2.72 & 1.70 & 0.98 & 0.65 & 0.54 & 0.34 & 0.24 \\
\hline 2 & 18.07 & 45.69 & 22.51 & 6.18 & 2.94 & 1.83 & 1.20 & 0.81 & 0.43 & 0.30 \\
\hline 3 & 7.63 & 15.30 & 41.14 & 21.25 & 7.04 & 3.53 & 1.92 & 1.16 & 0.65 & 0.34 \\
\hline 4 & 4.17 & 6.03 & 15.95 & 38.51 & 21.41 & 7.35 & 3.62 & 1.75 & 0.76 & 0.45 \\
\hline 5 & 2.78 & 2.92 & 6.49 & 17.88 & 36.64 & 20.99 & 7.54 & 2.92 & 1.25 & 0.56 \\
\hline 6 & 1.67 & 1.97 & 3.73 & 7.12 & 18.18 & 37.35 & 20.20 & 6.62 & 2.34 & 0.81 \\
\hline 7 & 1.23 & 1.15 & 1.85 & 3.52 & 7.07 & 18.30 & 39.97 & 20.10 & 5.32 & 1.52 \\
\hline 8 & 1.05 & 0.82 & 1.26 & 1.61 & 3.01 & 6.40 & 18.38 & 45.18 & 19.05 & 3.21 \\
\hline 9 & 0.97 & 0.56 & 0.77 & 0.77 & 1.46 & 2.40 & 5.03 & 17.77 & 55.35 & 14.94 \\
\hline 10 & 0.52 & 0.47 & 0.37 & 0.43 & 0.56 & 0.87 & 1.51 & 3.16 & 14.49 & 77.62 \\
\hline
\end{tabular}

Note: Panel A of Table C.1 reports regression coefficients and t-statistics for gross labor income deciles estimated using the SOEP (see text); all coefficients are significant at the 1\% level. Panel B shows the standard deviation of differences between annual logs of labor income and the regression's fitted values within each income level. Panel $\mathrm{C}$ depicts the conditional transition probabilities $q_{s_{t}, s_{t+1}}$ from the individual's current income level $s_{t}$ to all possible future income levels $s_{t+1}$. The darkness of the shading is proportional to the transition probability. Standard deviations and transition probabilities are assumed to be age-invariant. Observations with implied hourly wages below $80 \%$ of year 2015's minimum wage and employees working below 20 hours per week are excluded from the estimation. A minimum wage of $€ 8.50$ was introduced in 2015 (i.e. all SOEP observations are from the preminimum wage period) and omitting this data filter would result in inclusion of observations illegal under current law. 
Table C.2: Moments of Labor Income (Entire Workforce)

\begin{tabular}{|c|c|c|c|c|}
\hline Age & $25-34$ & $35-44$ & $45-54$ & $55-64$ \\
\hline \multicolumn{5}{|l|}{ Panel A: Mean } \\
\hline SOEP & 29.54 & 35.12 & 36.07 & 31.12 \\
\hline Markov chain & 33.76 & 38.07 & 39.62 & 37.90 \\
\hline Carroll and Samwick (1997) & 31.51 & 34.77 & 35.35 & 33.18 \\
\hline \multicolumn{5}{|l|}{ Panel B: Standard deviation } \\
\hline SOEP & 13.80 & 17.42 & 17.78 & 19.60 \\
\hline Markov chain & 13.64 & 18.34 & 20.35 & 19.06 \\
\hline Carroll and Samwick (1997) & 8.40 & 13.93 & 17.85 & 19.82 \\
\hline \multicolumn{5}{|l|}{ Panel C: Skewness } \\
\hline SOEP & 0.15 & 0.73 & 0.79 & 0.76 \\
\hline Markov chain & 0.91 & 1.17 & 1.24 & 1.13 \\
\hline Carroll and Samwick (1997) & 0.81 & 1.25 & 1.64 & 2.06 \\
\hline \multicolumn{5}{|l|}{ Panel D: Kurtosis } \\
\hline SOEP & 2.73 & 3.43 & 3.50 & 3.22 \\
\hline Markov chain & 4.12 & 4.51 & 4.58 & 4.29 \\
\hline Carroll and Samwick (1997) & 4.27 & 5.89 & 8.08 & 12.41 \\
\hline
\end{tabular}

Note: Table C.2 reports the empirical moments of labor income for observed SOEP data as well as for two datagenerating processes. Annual labor income measured in $€ 1,000$ refers to the total workforce. The method denoted 'Markov chain' is employed in the model (discussed in Section 3.3). The benchmark method is from Carroll and Samwick (1997) using the regression model $\ln Y_{i, t}=\gamma_{0}+\gamma_{1} \cdot \frac{a g e_{i, t}}{100}+\gamma_{2} \cdot \frac{a g e_{i, t}^{2}}{(100)^{2}}+u_{i, t}$ and resulting coefficients $\gamma_{0}=2.6926, \gamma_{1}=3.7645, \gamma_{2}=-4.0241$ (all significant at the $1 \%$ level); the variance of the permanent income shock $\sigma_{n}^{2}=1.69 \%$ and variance of the transitory income shock $\sigma_{u}^{2}=5.84 \%$. Using Carroll and Samwick's method, Fuchs-Schündeln et al. (2010) and Krebs and Yao (2016) find similar permanent, but higher transitory shock components for Germany. The lower transitory shock in our estimation is attributed to the additional data filters applied (outlined in Table C.1). Reported numbers are mean values over age ranges of 10 years from 100,000 simulation paths. 


\section{Online Appendix D: Parameter Matching: Base Case}

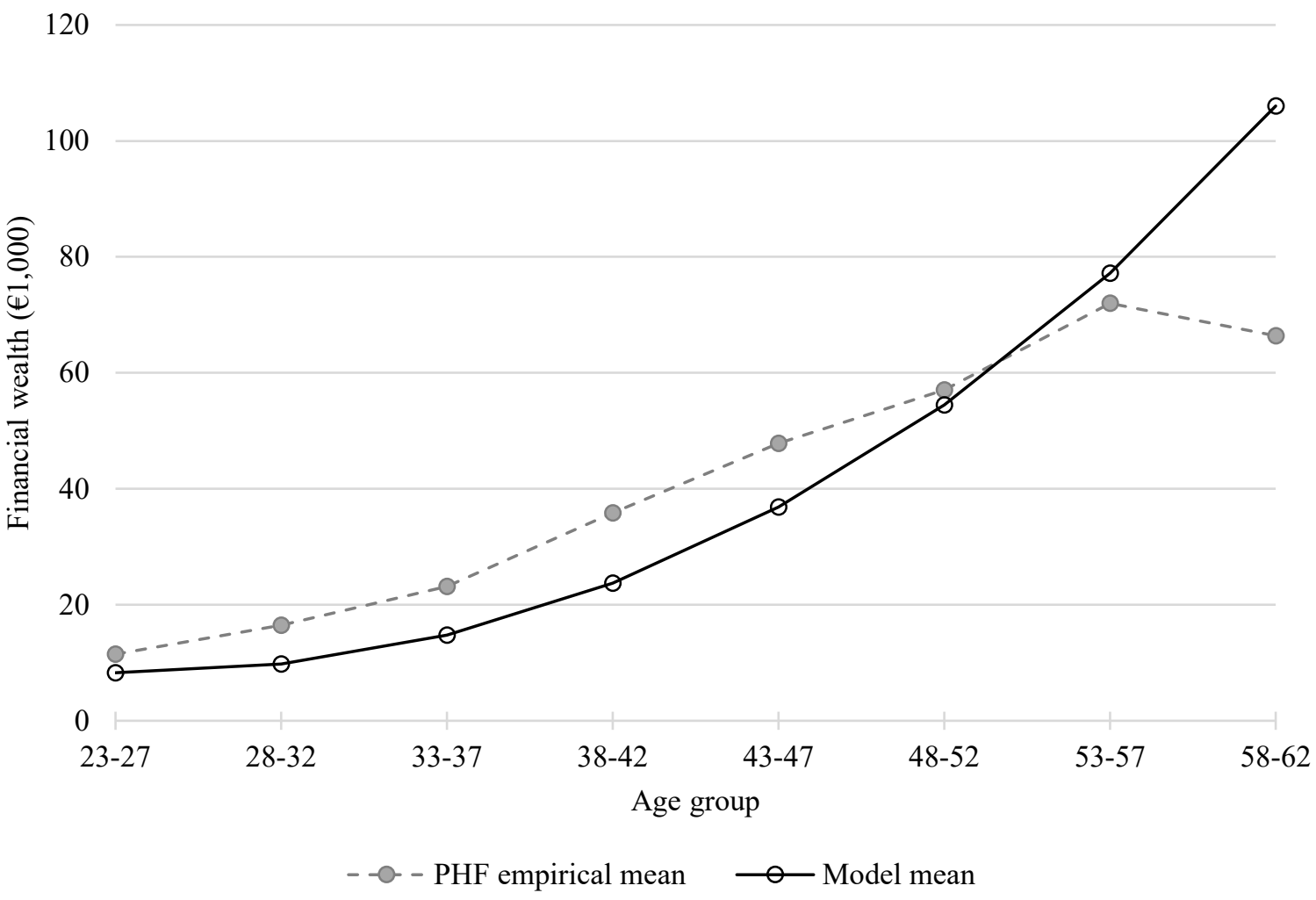

Note: The Figure shows the value of accumulated financial assets by age in Deutsche Bundesbank's Panel on Household Finances (PHF) and mean asset holdings generated from the model. Relying on a matching procedure related to Love (2010), the calibration with regard to the discount factor $\beta$ and the coefficient of relative risk aversion $\gamma$ is chosen such that the sum of relative squared differences between empirical observations and model wealth (in real terms) is minimized for five year age groups centered around age 25 to age 60 . For the matching procedure, we use Riester IRAs embedding an investment guarantee, a nominal risk-free interest rate of 3\%, inflation of $1.75 \%$, and an equity risk premium of $6 \%$ (with volatility of $21.41 \%$ ). The best fit is achieved by a discount factor of $\beta=0.93$ combined with relative risk aversion of $\gamma=7$. Financial wealth derived from PHF comprises all forms of fixed income, equity, pension accounts, and other investments (including real estate funds, managed accounts, etc.), while model wealth is the sum of direct stock and bond holdings plus IRA balances. As the PHF reports asset holdings other than IRAs only at the household level, individual values are derived by dividing household assets by two if a spouse is present and then adding individual pension accounts. 


\section{Online Appendix E: Results with Epstein-Zin-Weil Preferences, and with Front-End Loads on Contributions}

The use of CRRA preferences links the coefficient of risk aversion $(\gamma)$ and the elasticity of intertemporal substitution (EIS), inasmuch as one is the inverse of the other. To free up these parameters, we also investigate results using the Epstein-Zin-Weil utility formulation (Epstein and Zin, 1989; Weil, 1989); this approach allows independent preferences for smoothing across time and states. Here, consumption differences for the alternative guarantee designs are affected in two ways. First, lowering (increasing) the EIS means relative risk aversion is smaller (larger) than 1/EIS, so the individual will devote less (more) emphasis on consumption smoothing across states, compared to CRRA preferences. This should decrease (increase) the overall demand for saving and narrow (increase) differences in resulting retiree consumption under the guarantee. Second, the relative attractiveness of the scheme with/without guarantee changes. The guaranteed IRA provides smaller variation in payouts, but it also pays off less compared to the non-guaranteed IRA. For low (higher) levels of EIS, this makes the guaranteed IRA less (more) attractive relative to the non-guaranteed IRA, due to the consumer's weaker preference for smoothing across states.

Two effects work in opposite directions, so it is theoretically unclear which effect dominates. To resolve this, the first four columns of Table E.1 provide results using EpsteinZin-Weil preferences (as in Córdoba and Ripoll, 2017) for the base case calibration. Holding fixed the coefficient of relative risk aversion, we then reduce (increase) the CRRA-implied $E I S=1 / \gamma=1 / 7$ to $0.1(0.2)$, to permit an assessment of changing the EIS on IRA and liquid savings demand, and on resulting consumption opportunities. Lowering the EIS produces a substantial decline in total savings, by about 13\% between ages 60-79 (Panels B and C) relative to the CRRA case with the IRA guarantee, and an even larger reduction, of about $18 \%$, relative to the CRRA case and no guarantee (Table 5, columns 1 and 2). ${ }^{41}$ Moreover, for both guarantee designs, the IRA share as percent of total assets falls between 3.3 and 6.5 percentage points. ${ }^{42}$ Accordingly, removing the guarantee enhances savers' wellbeing less, driven by the substantial reduction in overall savings more than by a change in relative attractiveness of the two guarantee designs.

When the EIS is increased to 0.2 , the opposite effects obtain. Total saving rises by $25 \%$ for the guarantee case, due to the stronger demand for smoothing across states compared to results using CRRA parameters. The IRA provides better smoothing across states than liquid savings, due to the embedded deferred annuity, so a higher EIS value translates to more of the portfolio being held in the IRA. The IRA share as a percent of total assets rises slightly more, by $6.4 \%$ for the guaranteed IRA versus $5.7 \%$ for the non-guaranteed scheme. The consumption improvement resulting from removing the IRA guarantee is greater when the EIS rises, relative to the CRRA case.

In sum, of the two channels through which EIS affects consumption, the adjustment in total savings dominates the effect of changing the guarantee's attractiveness. Also, the positive effect of abolishing the guarantee rises when the EIS is higher, meaning that individuals favor consumption smoothing more strongly across states. Somewhat counterintuitively, the guaranteed IRA that smooths consumption more loses ground to the non-guaranteed alternative, because the increased consumption gained by abolishing the guarantee compensates for the individual's benefit of smoother consumption. In summary, then, results using Epstein-ZinWeil preferences confirm the conclusions of prior sections: a non-guaranteed IRA considerably enhances consumption relative to that feasible with a guaranteed IRA.

\footnotetext{
${ }^{41}$ As the IRA is fully depleted beyond age 84 , asset holdings in the final periods cannot be analyzed accurately.

${ }^{42}$ For the guarantee case, it falls from $70.4 \%$ to $67.0 \%$, and with no guarantee, from $73.6 \%$ to $67.1 \%$.
} 
Moreover, thus far we have abstracted from sales charges levied on IRA contributions, yet in the German context, investing in an IRA requires payment of front-end loads (no fees are charged on redemptions during the payout phase). Such fees could affect the demand for guarantees for two reasons. First, the loads might render the IRAs so unattractive that savers could contribute little or nothing. In such a case, the guarantee specifications become irrelevant. Second, the loads could interact with expensive guarantee costs and discourage IRA investors from contributing. In this latter case, the IRA's appeal would be enhanced by abolishing the guarantee, and consumption without a guaranteed IRA might be even greater than with the guarantee (as illustrated in Section 4).

The final two columns of Table E.1 document that IRA investments are still substantial, even with a front-end load of $5 \%$ on contributions. Yet unsurprisingly, Panels $\mathrm{C}$ and $\mathrm{D}$ show that such loads lead to less IRA wealth accumulated for the base calibration; as a consequence, payouts are also lower than in the absence of such fees (compare the first two columns of Table 5). Importantly, participant contributions do not decline symmetrically. Given the front end load, lifetime contributions with the guarantee fall by $6.9 \%$ (to $€ 20,850$ ); without the guarantee, contributions drop by only about $3.2 \%$ (to $€ 22,400$ ). ${ }^{43}$ IRA payouts differ by $10-11 \%$ without the extra loads, but by $13 \%$ when front-end loads are taken into account. As a result, old-age consumption differences are greater than without fees. Overall, with realistic sales loads, the negative consequences of the IRA guarantees are slightly worse.

\footnotetext{
${ }^{43}$ Intuitively, with fees average timing of contributions is a little earlier to give invested capital more time to earn return (about 0.74 years earlier with a money-back guarantee and 0.32 years in absence of a guarantee).
} 
Table E.1: Sensitivity Analysis for Different Preferences and Fees: Base Case

\begin{tabular}{|c|c|c|c|c|c|c|}
\hline \multirow{2}{*}{$\frac{\text { Specification }}{\text { Guarantee }}$} & \multicolumn{2}{|c|}{ EZW: lower EIS } & \multicolumn{2}{|c|}{ EZW: higher EIS } & \multicolumn{2}{|c|}{ Front-end load: $5 \%$} \\
\hline & With & Without & With & Without & With & Without \\
\hline \multicolumn{7}{|c|}{ Panel A: Consumption (in $€ 1,000$ or percent of guarantee case) } \\
\hline Age $25-39$ & 15.36 & $100 \%$ & 15.02 & $100 \%$ & 15.22 & $100 \%$ \\
\hline Age $40-59$ & 16.24 & $100 \%$ & 16.25 & $100 \%$ & 16.22 & $100 \%$ \\
\hline Age $60-79$ & 15.15 & $101 \%$ & 16.47 & $102 \%$ & 15.51 & $101 \%$ \\
\hline Age $80-100$ & 13.51 & $101 \%$ & 16.63 & $104 \%$ & 14.14 & $104 \%$ \\
\hline
\end{tabular}

Panel B: Liquid Savings (in $€ 1,000$ or percent of guarantee case)

$\begin{array}{lrrrrrr}\text { Age } 25-39 & 9.02 & 101 \% & 11.01 & 98 \% & 10.11 & 98 \% \\ \text { Age 40-59 } & 22.59 & 104 \% & 26.04 & 99 \% & 25.21 & 97 \% \\ \text { Age 60-79 } & 27.74 & 101 \% & 28.14 & 94 \% & 30.60 & 92 \% \\ \text { Age } 80-100 & 1.86 & 94 \% & 2.97 & 100 \% & 2.51 & 86 \%\end{array}$

Panel C: IRA Balance (in $€ 1,000$ or percent of guarantee case)

\begin{tabular}{|c|c|c|c|c|c|c|}
\hline Age $25-39$ & 1.72 & $94 \%$ & 4.55 & $110 \%$ & 2.46 & $109 \%$ \\
\hline Age $40-59$ & 24.35 & $99 \%$ & 44.83 & $109 \%$ & 28.95 & $111 \%$ \\
\hline Age $60-79$ & 56.39 & $101 \%$ & 92.83 & $110 \%$ & 62.43 & $113 \%$ \\
\hline Age $80-84$ & 12.97 & $101 \%$ & 21.59 & $110 \%$ & 14.40 & $113 \%$ \\
\hline
\end{tabular}

Panel D: IRA Payouts (in $€ 1,000$ or percent of guarantee case)

$\begin{array}{lrrrrrr}\text { Age 67: lump sum } & 14.09 & 100 \% & 20.97 & 110 \% & 14.67 & 113 \% \\ \text { Age 68-84: drawdown } & 4.44 & 101 \% & 7.37 & 110 \% & 4.94 & 113 \% \\ \text { Age 85-100: annuity } & 7.53 & 101 \% & 12.26 & 110 \% & 8.26 & 113 \%\end{array}$

Panel E: Share of Consumption and Housing Costs Financed by IRA Payouts (\%)

$\begin{array}{lllllll}\text { Age 68-84: drawdown } & 17.3 & 17.5 & 25.6 & 27.5 & 18.7 & 20.8 \\ \text { Age 85-100: annuity } & 30.0 & 30.3 & 41.0 & 43.3 & 31.9 & 34.8\end{array}$

Panel F: IRA Shortfall Probability (\%)
Age 67
0.0
7.9
0.0
4.9
0.0
7.5

Note: Panels A-D of Table E.1 report mean values (in $€ 1,000)$ of annual non-housing consumption, liquid assets, IRA balances, and payouts, by age ranges, for three different cases with and without guarantee (the latter as percent of the guarantee case). Panel E quantifies the share (in \%) of both consumption and housing costs which is financed by after-tax payouts from the IRA. Panel F reports the share of simulations where the IRA value at retirement falls short of the sum of contributions and subsidies. In the first and second case, we allow for Epstein-Zin-Weil (EZW) preferences in order to disentangle risk aversion and elasticity of intertemporal substitution (EIS). Starting from the CRRA-implied EIS of $\psi=1 / 7=0.1429$ in the first (second) specification, EIS is decreased (increased) to $0.1(0.2)$ while holding relative risk aversion constant at $\gamma=7$. In the third specification a front-end load of 5\% for each contribution (including subsidies) is charged. In all specifications, the nominal risk-free rate and inflation rate are assumed constant at $i_{f}=3 \%$ and $\pi=1.75 \%$, and the equity risk premium is $6 \%$ (with volatility of $21.41 \%$ ). 


\section{Online Appendix F: Illustrating How to Generalize to Other Countries}

The results presented in the body of the paper are based on a model calibration which reflects the specific regulations of the Riester IRA, as well as the German institutional framework. In this appendix, we confirm that the negative implications of a mandatory moneyback IRA guarantee are not due to uniquely German economic factors, but rather are relevant to other countries as well.

Despite cross-national differences in tax systems, most developed countries have progressive income taxes under which high earners are subject to higher tax rates than lower earners (see Bunn and Asen, 2020; and Online Appendix A for the German case). Most developed nations also require contributions to a mandatory state-run pay-as-you-go plan automatically deducted from payrolls that entitle retirees to a lifelong pension income stream. Access to health insurance usually is gained from automatic payroll deductions, while, of course, the costs and levels of coverage vary. The German multi-payer health insurance system, which is financed via payroll deductions also has insurers facing competition to attract customers; as such, it falls between the centrally organized single-payer system common in the EU, and the mostly market-based system of the U.S. (Hussey and Anderson, 2003; Thomson et al., 2013). Therefore, the German tax and social security system can be seen as relevant for many developed countries.

To generalize the setup of the IRA beyond the German Riester, here we make two adjustments. First, we assume no payment of subsidies, but we keep the tax deductibility of contributions of up to $€ 2,100$ per year. Exclusion of the subsidy is motivated by the argument that IRAs are not usually accompanied by matching of contributions by a generous third party (like the government in case of the Riester IRA, or the employer in U.S. 401(k) plans). Second, we allow for flexible withdrawals during the entire decumulation phase. We retain the deferred annuity within the retirement account, as in the German case, since the recent passage of the SECURE Act in the United States has rendered these insurance products an accepted default solution (Horneff et al., 2020). Moreover, the literature agrees that annuities are an effective means of controlling longevity risks (e.g., Davidoff et al., 2005; Horneff et al., 2008). Both adjustments to the IRA harmonize its setup with respect to international standards. The absence of subsidies in the model results in lower demand for the IRA, but the less restrictive withdrawal rules make the account more valuable.

Analogous to Figure 3, the path-wise consumption differences between the internationally harmonized IRA with and without guarantee is shown in Figure F.1 for the normal interest rate scenario. The average consumption improvement from abolishing the guarantee remains positive and economically significant. By the end of the accumulation phase, the average consumption surplus without a guarantee has grown to $1.04 \%$, and from age 68 to 84 it amounts to about $1.9 \%$. After the deferred annuity starts paying, the consumption surplus increases to $4.6-5.0 \%$ per year.

Compared to the German IRA setup, consumption differences until retirement are almost unaltered. Due to the flexible withdrawals permitted in this internationally harmonized IRA, the consumption surplus is about 0.4 percentage points higher in the first 11 years of retirement. Consumption for both the German and the internationally harmonized setup rises strongly at age 85 when the deferred annuity starts paying yet the increase is stronger for the internationally harmonized IRA. This is the consequence of a seemingly higher relative attractiveness of the no-guarantee versus the guarantee IRA in the international setup. In that context, IRA savings at retirement and annuity payouts without the guarantee compared to the guarantee case are three percentage points higher than in the German setup (14\% versus 11\%), leading to superior consumption improvements at highest ages. In summary, with respect to the variation of 
consumption surpluses around the mean, there are no substantial differences between results with the Riester model and with the internationally harmonized IRA.

Table F.1 quantifies the differences in consumption, liquid asset holdings, and IRA balances and payouts for the internationally harmonized IRA, for comparison with the Riester results in Table 5. Overall, the effects of abolishing the guarantee on consumption are even larger for the internationally harmonized IRA, yet IRA balances are lower, indicating that the benefits from allowing self-selected withdrawals do not offset the lack of subsidies. The slightly higher consumption difference in the low interest rate scenario for the internationally harmonized IRA from age 60-79 results from the fact that allowing flexible withdrawals causes more front-loaded payouts.

These adjustments have been tailored to reflect a more general framework for the IRA environment, yet the results show that a money-back guarantee also in this more flexible case erodes most participants' average consumption.

Figure F.1: Consumption Differences and Percent Better off by Age Without versus With the IRA Guarantee: International Context (Base Case)
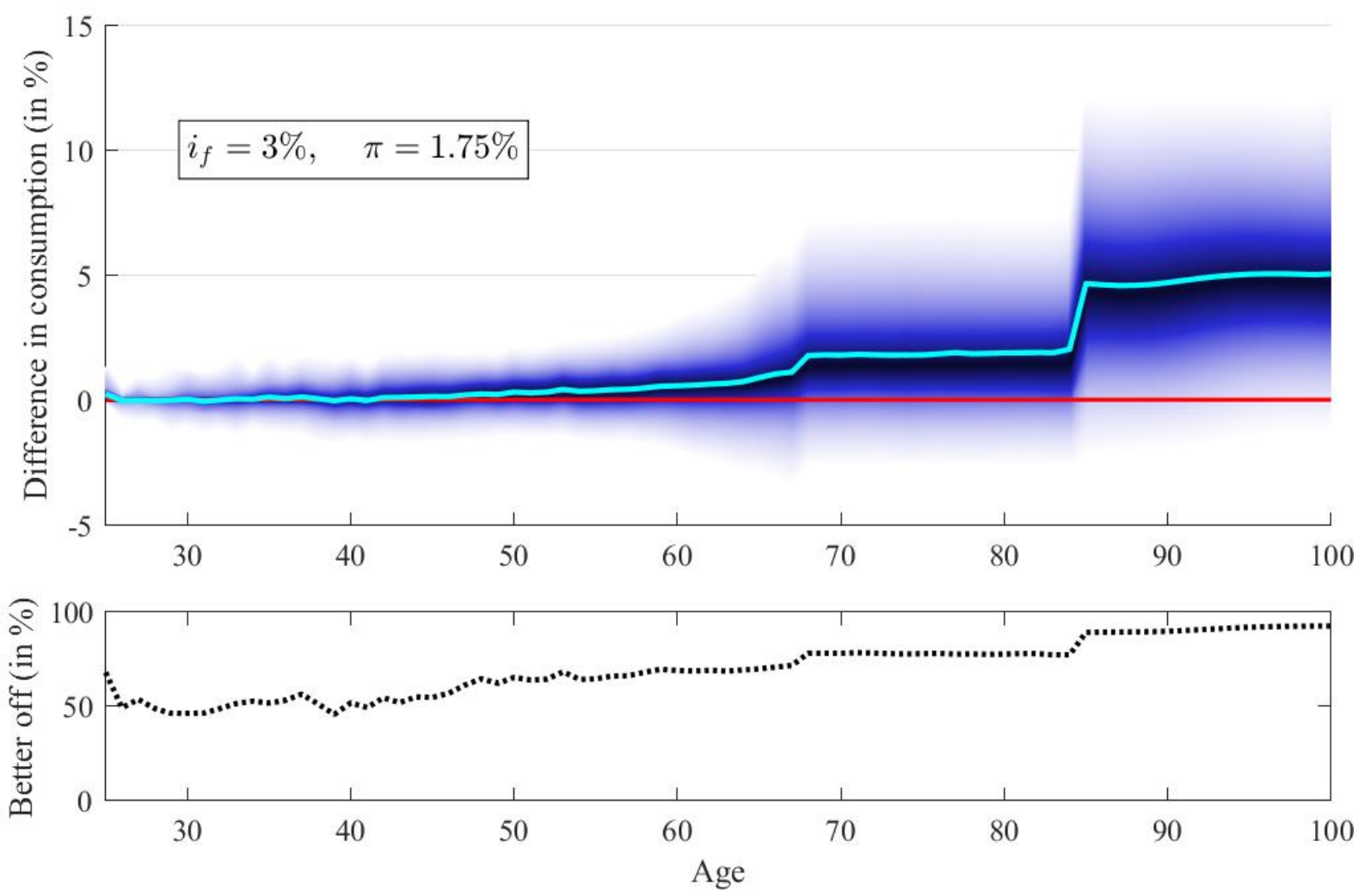

Note: The fan chart at the top of the Figure F.1 illustrates path-wise differences in non-housing consumption drawn from 100,000 simulated optimal life cycles for internationally harmonized IRAs without versus with a moneyback guarantee. For the internationally harmonized IRA in comparison to the Riester IRA two changes are assumed. First, the account is not subsidized by any matching contributions; and second, the participant can freely decide on withdrawals from age 67 until age 84 . The cyan line represents the mean consumption difference, while darker areas indicate a higher probability density (between the 5 and $95 \%$ quantiles). Differences are expressed as a percent of optimal consumption with the money-back guarantee. The bottom panel shows the percentage of individuals with higher optimal consumption without versus with the money-back guarantee. For further notes on base case parameters see Figure 1. 
Table F.1: Impacts of Different Guarantees: International Context

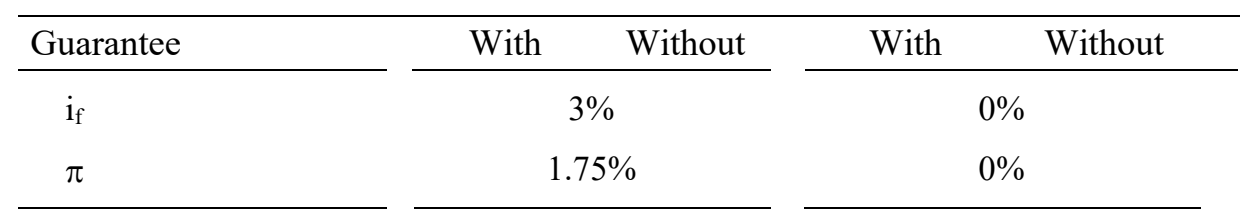

Panel A: Consumption (in $€ 1,000$ or percent of guarantee case)

$\begin{array}{lllll}\text { Age } 25-39 & 15.22 & 100 \% & 15.15 & 100 \% \\ \text { Age } 40-59 & 16.21 & 100 \% & 15.84 & 101 \% \\ \text { Age } 60-79 & 15.60 & 102 \% & 14.21 & 104 \% \\ \text { Age } 80-100 & 14.40 & 105 \% & 11.05 & 111 \%\end{array}$

Panel B: Liquid Savings (in $€ 1,000$ or percent of guarantee case)

$\begin{array}{lrrrr}\text { Age } 25-39 & 9.79 & 98 \% & 10.97 & 94 \% \\ \text { Age } 40-59 & 24.18 & 98 \% & 32.21 & 87 \% \\ \text { Age } 60-79 & 31.08 & 93 \% & 44.49 & 84 \% \\ \text { Age } 80-100 & 3.00 & 92 \% & 4.69 & 80 \%\end{array}$

Panel C: IRA Balance (in $€ 1,000$ or percent of guarantee case)

$\begin{array}{rrrrr}\text { Age } 25-39 & 2.71 & 119 \% & 0.58 & 360 \% \\ \text { Age 40-59 } & 30.14 & 112 \% & 9.84 & 227 \% \\ \text { Age 60-79 } & 61.22 & 114 \% & 19.90 & 194 \% \\ \text { Age 80-84 } & 9.21 & 115 \% & 1.42 & 218 \%\end{array}$

Panel D: IRA Payouts (in $€ 1,000$ or percent of guarantee case)

$\begin{array}{lrrrr}\text { Age 67: withdrawal } & 12.42 & 111 \% & 7.68 & 144 \% \\ \text { Age 68-84: withdrawal } & 5.21 & 114 \% & 1.63 & 190 \% \\ \text { Age 85-100: annuity } & 8.70 & 114 \% & 2.85 & 179 \%\end{array}$

Panel E: Share of Consumption and Housing Costs Financed by IRA Payouts (\%)

$\begin{array}{llrrr}\text { Age 68-84: withdrawal } & 22.0 & 24.6 & 8.7 & 15.4 \\ \text { Age 85-100: annuity } & 31.3 & 34.2 & 12.3 & 20.4\end{array}$

Panel F: IRA Shortfall Probability (\%)
Age 67
6.4
0.0
18.5

0.0

Note: Panels A-D of Table F.1 show mean values (in $€ 1,000$ ) of annual non-housing consumption, liquid assets, IRA balances, and payouts, by age ranges for an internationally harmonized IRA for which in comparison to the Riester IRA two changes are assumed. First, the account is not subsidized by any matching contributions; and second, the participant can freely decide on withdrawals from age 67 until age 84. Results for columns labeled 'Without' indicate the percent of the respective guarantee values. Panel E quantifies the share (in \%) of both consumption and housing costs financed by after-tax payouts from the IRA. Panel F reports the share of simulations where the IRA value at retirement falls short of the sum of contributions and subsidies. IRA assets are held entirely in stocks until retirement (protected with the hedges described above), while after retirement only $20 \%$ is allocated to stocks and $80 \%$ to bonds. Averages are generated using 100,000 simulation optimal life cycle paths (all in real terms). For further notes on base case parameters see Figure 1. 


\section{References for the Online Appendix}

Bunn, D. and E. Asen (2020). "International Tax Competitiveness Index." Accessed 08-Feb2021. https://files.taxfoundation.org/20201009154525/2020-International-TaxCompetitiveness-Index.pdf

Carroll, C. D. and A. A. Samwick (1997). "The Nature of Precautionary Wealth.” Journal of Monetary Economics 40(1): 41-71.

Córdoba, J. C. and M. Ripoll (2017). "Risk Aversion and the Value of Life." Review of Economic Studies 84(4): 1472-1509.

Davidoff, T., J. R. Brown, and P. A. Diamond (2005). "Annuities and Individual Welfare." American Economic Review 95(5): 1573-1590.

Epstein, L. G. and S. E. Zin (1989). "Substitution, Risk Aversion, and the Temporal Behavior of Consumption and Asset Returns: A Theoretical Framework." Econometrica 57(4): 937-969.

Fuchs-Schündeln, N., D. Krueger, and M. Sommer (2010). "Inequality Trends for Germany in the Last Two Decades: A Tale of Two Countries." Review of Economic Dynamics 13(1): 103-132.

Horneff, V., R. Maurer, and O. S. Mitchell (2020). "Putting the Pension Back in 401(k) Retirement Plans: Optimal versus Default Deferred Longevity Income Annuities." Journal of Banking \& Finance 114. https://doi.org/10.1016/j.jbankfin.2020.105783

Horneff, W., R. Maurer, and M. Stamos (2008). "Life-Cycle Asset Allocation with Annuity Markets." Journal of Economic Dynamics and Control 32(11): 3590-3612.

Hussey, P. S. and G. F. Anderson (2003). "A Comparison of Single- and Multi-Payer Health Insurance Systems and Options for Reform." Health Policy 66(3): 215-228.

Krebs, T. and Y. Yao (2016). "Labor Market Risk in Germany.” IZA Discussion Paper No. 9869.

Love, D. A. (2010). "The Effects of Marital Status and Children on Savings and Portfolio Choice." Review of Financial Studies 23(1): 385-432.

Thomson, S., R. Busse, L. Crivelli, W. van de Ven, and C. Van de Voorde (2013). "Statutory Health Insurance Competition in Europe: A Four-Country Comparison." Health Policy 109(3): 209-225.

Weil, P. (1989). “The Equity Premium Puzzle and the Risk-Free Rate Puzzle." Journal of Monetary Economics 24(3): 401-421. 